\title{
Boron-Coated Straw Collar for Uranium Neutron Coincidence Collar Replacement
}

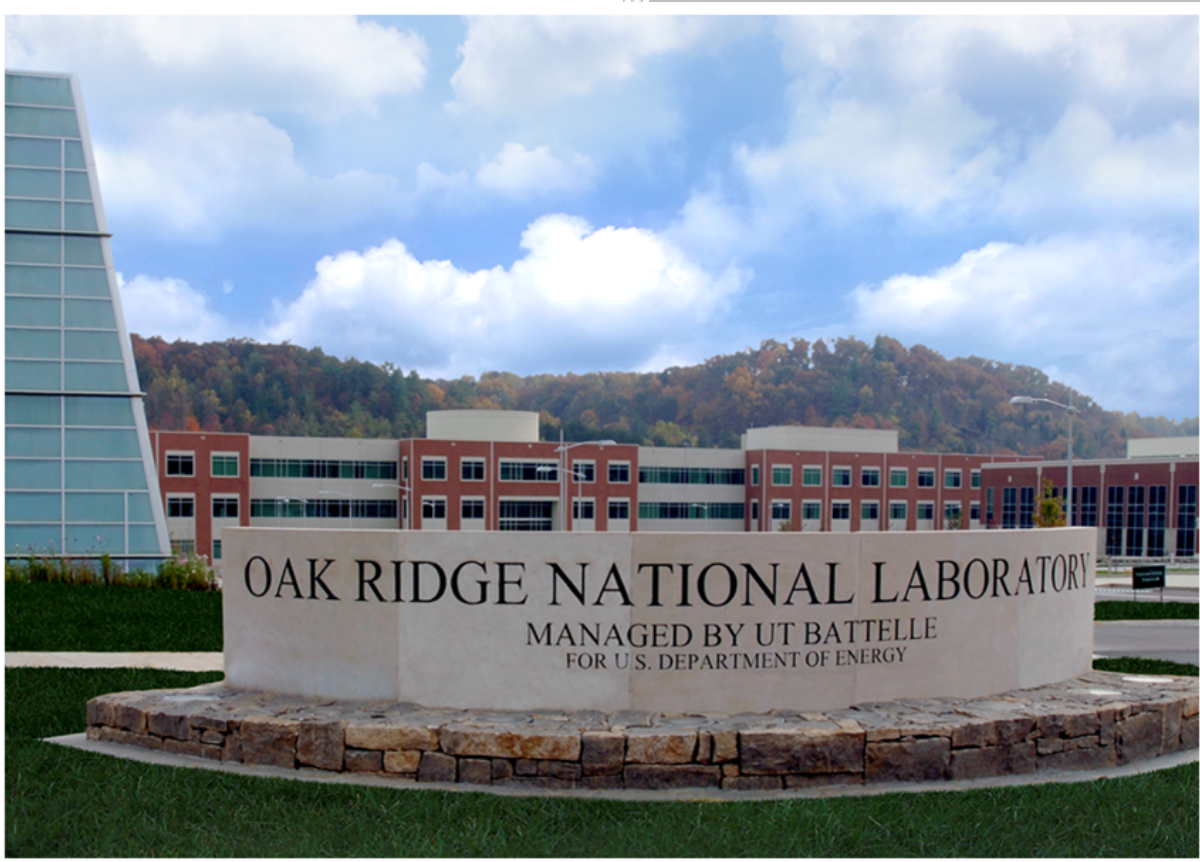

Jianwei Hu

Stephen Croft

Robert McElroy

December 31, 2016 


\title{
DOCUMENT AVAILABILITY
}

Reports produced after January 1, 1996, are generally available free via US Department of Energy (DOE) SciTech Connect.

\section{Website http://www.osti.gov/scitech/}

Reports produced before January 1, 1996, may be purchased by members of the public from the following source:

\author{
National Technical Information Service \\ 5285 Port Royal Road \\ Springfield, VA 22161 \\ Telephone 703-605-6000 (1-800-553-6847) \\ TDD 703-487-4639 \\ Fax 703-605-6900 \\ E-mail info@ntis.gov \\ Website http://classic.ntis.gov/
}

Reports are available to DOE employees, DOE contractors, Energy Technology Data Exchange representatives, and International Nuclear Information System representatives from the following source:

Office of Scientific and Technical Information

PO Box 62

Oak Ridge, TN 37831

Telephone 865-576-8401

Fax 865-576-5728

E-mail reports@osti.gov

Website http://www.osti.gov/contact.html

This report was prepared as an account of work sponsored by an agency of the United States Government. Neither the United States Government nor any agency thereof, nor any of their employees, makes any warranty, express or implied, or assumes any legal liability or responsibility for the accuracy, completeness, or usefulness of any information, apparatus, product, or process disclosed, or represents that its use would not infringe privately owned rights. Reference herein to any specific commercial product, process, or service by trade name, trademark, manufacturer, or otherwise, does not necessarily constitute or imply its endorsement, recommendation, or favoring by the United States Government or any agency thereof. The views and opinions of authors expressed herein do not necessarily state or reflect those of the United States Government or any agency thereof. 
Reactor and Nuclear Systems Division

\title{
BORON-COATED STRAW COLLAR FOR URANIUM NEUTRON COINCIDENCE COLLAR REPLACEMENT
}

\author{
Jianwei $\mathrm{Hu}$ \\ Stephen Croft \\ Robert McElroy
}

Date Published: December 31, 2016

\author{
Prepared by \\ OAK RIDGE NATIONAL LABORATORY \\ Oak Ridge, TN 37831-6283 \\ managed by \\ UT-BATTELLE, LLC \\ for the \\ US DEPARTMENT OF ENERGY \\ under contract DE-AC05-00OR22725
}





\section{CONTENTS}





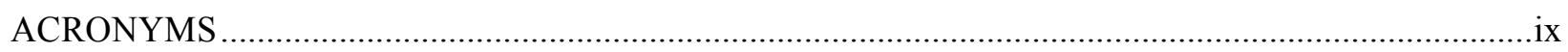

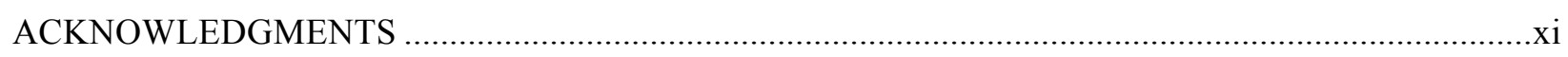

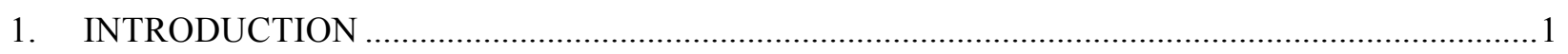

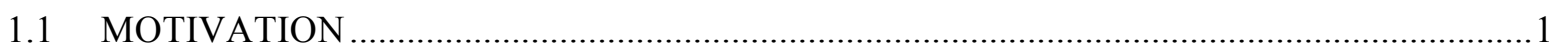

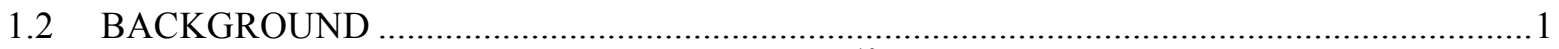

1.3 ADVANTAGES AND DISADVANTAGES OF ${ }^{10} \mathrm{~B}$-LINED COUNTERS FOR

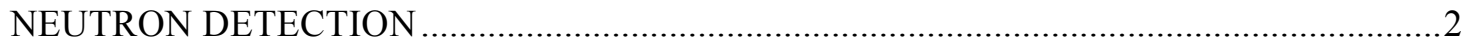

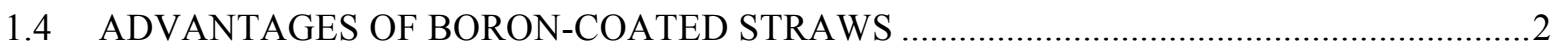

1.5 A BCS-BASED HIGH-LEVEL NEUTRON COINCIDENCE COUNTER

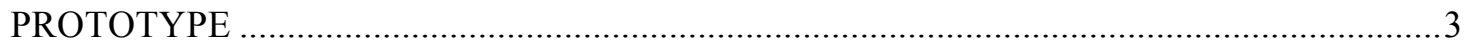

2. CONCEPTUAL DESIGNS OF THE BCS-BASED COLLARS FOR UNCL

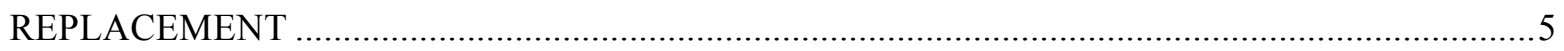

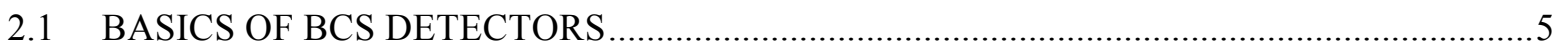

2.2 THE BASE MODEL OF THE BORON-COATED-STRAW COLLAR …..............................

2.3 THE "PLUS" MODEL OF THE BORON-COATED-STRAW COLLAR …............................

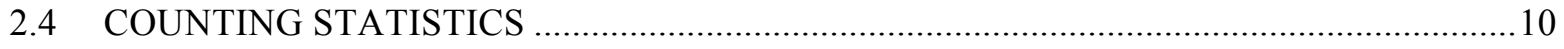

2.5 OPTIMIZATIONS FOR DETECTION EFFICIENTLY AND SOURCE-FUEL

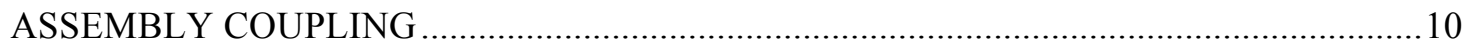

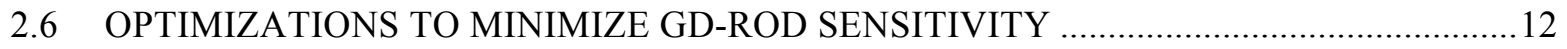

3. TEST RESULTS OF THE BORON-COATED STRAW PLUS COLLAR …...............................19

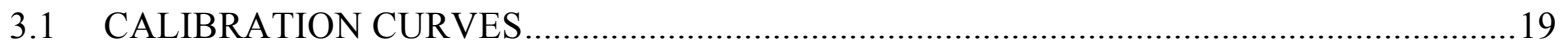

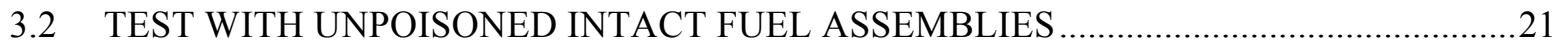

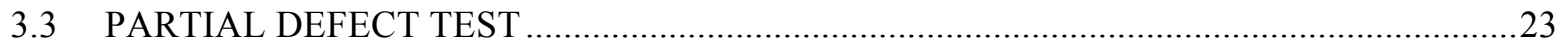

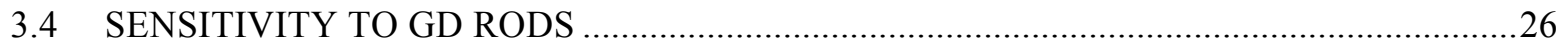

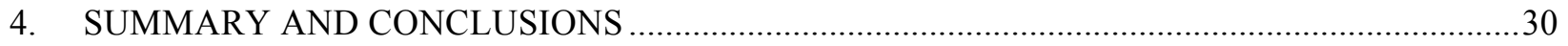

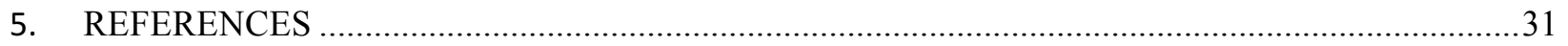







\section{LIST OF FIGURES}

Figure 1. BCS-based HLNCC prototype (a, b), sealed BCS detectors (c), and the polyethylene body with holes to accommodate the BCS detectors (d) [11].

Figure 2. The basic straw design (round) and three advanced straw designs: (a) the basic straw design (left) and the (advanced) six-point star, (b) pie-6, and (c) pie-12. The six-point star, pie- 6 , and pie-12 increase the total boron coating area by a factor of $1.4,2.0$, and 3.0, respectively, compared with the basic design

Figure 3. Probability of energy deposition with various boron coating layer thicknesses after a neutron absorption event takes place in the layer.

Figure 4. The electronic efficiency factor (EEF) for neutrons of the boron-coated-straw detector as a function of boron coating thickness.

Figure 5. Base model BCS collar compared with the Uranium Neutron Coincidence Collar-II (UNCL-II): BCS base collar with a fuel assembly in the middle (a); configuration and dimensions of UNCL-II (b) [1].

Figure 6. BCS plus collar: the XY cross-sectional view of the BCS plus collar (a); the XZ crosssectional view of the plus collar with the Y plane cutting through the AmLi source (b).

Figure 7. Microscopic neutron cross section (barns) for ${ }^{155} \mathrm{Gd}$ absorption, ${ }^{235} \mathrm{U}$ fission, ${ }^{112} \mathrm{Cd}$ absorption, and ${ }^{238} \mathrm{U}$ fission reactions as a function of incident neutron energy. ..........................13

Figure 8. Neutron energy spectra of the AmLi source [16].

Figure 9. Parametric study of source block design to reduce sensitivity to Gd rods while increasing sensitivity to ${ }^{235} \mathrm{U}$.

Figure 10. The ratio of ${ }^{235} \mathrm{U}$ fission rate to the gadolinium absorption rate (left $\mathrm{Y}$-axis) and the ratio of the ${ }^{235} \mathrm{U}$ fission rate to the ${ }^{238} \mathrm{U}$ fission rate (right $\mathrm{Y}$-axis) for different combinations of polyethylene density, gadolinium liner thickness, and neutron reflector materials.

Figure 11. Calibration curve for the fast mode of the BCS plus collar compared with that of UNCL.

Figure 12. Calibration curve for the thermal mode of the BCS plus collar compared with that of $\mathrm{UNCL}$

Figure 13. The relative mass defects of 12 simulated unpoisoned intact fuel assemblies for the BCS plus collar (a) and UNCL (b).

Figure 14. The assemblies for the partial defect test. .....

Figure 15. The relative mass defects of five assemblies with different numbers of partial defects for the BCS plus collar (a) and UNCL (b).

Figure 16. Number and distribution of Gd rods in each of the six test assemblies. ................................26

Figure 17. Relative reductions in doubles rates due to the Gd rods in each fuel assembly......................22

Figure 18. The relative mass defects of 18 assemblies with different amounts of gadolinium for the BCS plus collar (a) and UNCL (b). 



\section{LIST OF TABLES}

Table 1. Measured performance parameters for different replacement technologies [11] ......................... 4

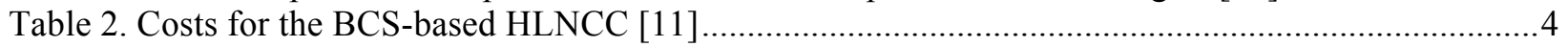

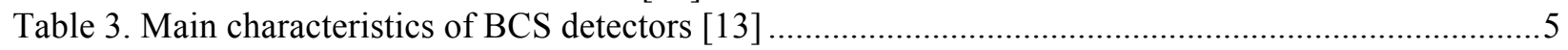

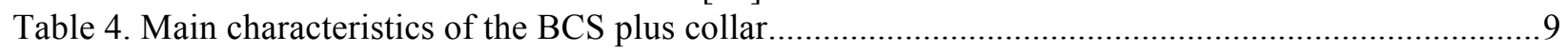

Table 5. Optimization of $\mathrm{B}_{4} \mathrm{C}$ coating thickness and straw pitch for the $\mathrm{BCS}$ collar ..............................12

Table 6. Optimization of source location (distance between the AmLi source and the cavity center)

Table 7. Comparison of performance among the boron-coated-straw and uranium-neutroncoincidence collars

Table 8. Results of the source block optimization study

Table 9. The impact of polyethylene density on Gd-rod sensitivity and counting precision of the boron-coated-straw collar

Table 10. Impact of gadolinium liner thickness of three sides of the cavity of the collar.......

Table 11. Impact of gadolinium liner thickness of the bottom side of the cavity of the collar

Table 12. Calculated Singles rates, Doubles rates, and RSD (for 10 min counting time) of the BCS plus collar (fast mode) as a function of ${ }^{235} \mathrm{U}$ liner density $(\mathrm{g} / \mathrm{cm})$ in the tested $17 \times$ 17 fresh fuel assemblies

Table 13. Calculated Singles rates, Doubles rates, and RSD (for 10 min counting time) of the BCS plus collar (thermal mode) as a function of ${ }^{235} \mathrm{U}$ liner density $(\mathrm{g} / \mathrm{cm})$ in the tested 1717 fresh fuel assemblies.

Table 14. Comparison of relative mass defects and RSDs for each partial defect case for the BCS plus collar and UNCL

Table 15. Comparison of relative mass defects and RSDs for each case with different gadolinium content for the BCS plus collar and UNCL 



\section{ACRONYMS}

$\varepsilon$

detection efficiency

BCS boron-coated straw

DU

depleted uranium

EEF

electronic efficiency factor

EFC

Euratom Fast Collar

Euratom

European Atomic Energy Community

FM

flux multiplication

FNCL

Fast Neutron Collar (IAEA)

FOM

figure of merit

HLNCC

high-level neutron coincidence counter

IAEA

International Atomic Energy Agency

INCC

IAEA neutron coincidence counting software

LD

linear density

MCNP

Monte Carlo N-particle

NDA

nondestructive assay

NNSA

National Nuclear Security Administration (US Department of Energy)

$\mathrm{PC}$

proportional counter

PTI

Proportional Technologies, Inc.

RSD

relative standard deviation

UNCL Uranium Neutron Coincidence Collar 



\section{ACKNOWLEDGMENTS}

This work was funded by the US Department of Energy (DOE) Office of Nonproliferation and Arms Control and the DOE National Nuclear Security Administration. The authors are grateful for the help from Mr. Athanasios Athanasiades and Dr. Jeff Lacy at Proportional Technologies, Inc., regarding design details of boron straws. The authors would also like to thank those who reviewed and helped to improve this report. 



\section{INTRODUCTION}

The objective of this project was to design and optimize, in simulation space, an active neutron coincidence counter (or collar) using boron-coated straws (BCSs) as a non- ${ }^{3} \mathrm{He}$ replacement to the Uranium Neutron Coincidence Collar (UNCL) [1]. UNCL has been used by the International Atomic Energy Agency (IAEA) and European Atomic Energy Community (Euratom) since the 1980s to verify the ${ }^{235} \mathrm{U}$ content in fresh light water reactor fuel assemblies for safeguards purposes. This report documents the design and optimization of the BCS collar.

\subsection{MOTIVATION}

UNCL consists of 18 to 241 ", 4 atmosphere, ${ }^{3} \mathrm{He}$ tubes, and it can be operated in both fast and thermal modes, with and without the use of a cadmium liner. In modern nuclear fuel assembly designs, more burnable poisons, including gadolinia $\left(\mathrm{Gd}_{2} \mathrm{O}_{3}\right)$, are used to balance the higher ${ }^{235} \mathrm{U}$ enrichment in the fuel to reduce the reactivity swing over the fuel's lifetime in a reactor. Fuel rods that contain $\mathrm{Gd}_{2} \mathrm{O}_{3}$ are often referred to as "Gd rods." Therefore, in this report, when $\mathrm{Gd}_{2} \mathrm{O}_{3}$-containing fuel rods are meant, "Gd rod" or "Gd rods" will be used. UNCL is sensitive to burnable poisons (e.g., Gd rods) contained in a fuel assembly in both modes, although to a lesser degree in the fast mode. Safeguards inspectors normally use correction factors to account for the reduced UNCL neutron count rates due to the presence of Gd rods in the measured fuel assemblies, so information about the number and content of the Gd rods is needed from the operator to make such corrections. This makes the safeguards inspection dependent, rather than independent (as desired), on operator declarations. Furthermore, intentionally misleading operator

declarations on $\mathrm{Gd}$ rods can be used to cover illicit diversion of special nuclear materials (e.g., $\left.{ }^{235} \mathrm{U}\right)$ from fresh fuel assemblies. Therefore, new instruments that are less sensitive to Gd rods are needed by safeguards authorities. The high and ever-increasing cost of ${ }^{3} \mathrm{He}$ gas has also been a driving force in the development of alternative technologies to replace the ${ }^{3} \mathrm{He}$-based UNCL instrument.

\subsection{BACKGROUND}

The need for UNCL replacement has been recognized internationally, and various efforts have been undertaken to develop alternatives to UNCL. For example, Evans et al. [2] have developed a fast neutron collar, referred to as the Euratom Fast Collar (EFC), in collaboration with Euratom and achieved a much higher efficiency than UNCL. However, EFC's sensitivity to Gd rods was not much improved compared with UNCL, even in fast mode, and still requires a significant correction factor for Gd rods (see details in subsection 3.3). In addition, EFC uses 331 1", 10 atmosphere, ${ }^{3} \mathrm{He}$ tubes, which is $\sim 3.6$ times more ${ }^{3} \mathrm{He}$ gas than UNCL. IAEA is developing a liquid scintillator-based fast neutron collar, referred to as the Fast Neutron Collar (FNCL) [3], for UNCL replacement. Although FNCL is ${ }^{3} \mathrm{He}$ free and has significantly less sensitivity to Gd rods than UNCL, its data acquisition system remains complex, and further development is required to ensure its reliability and stability before it becomes practical for routine inspections [3].

In FY 2016, the US Department of Energy National Nuclear Security Administration's (NNSA's) Office of Nonproliferation and Arms Control Office of International Nuclear Safeguards sponsored a research program to perform a comparative study using simulations to evaluate several alternative detector technologies for UNCL replacement. The list below shows the various technologies with the corresponding institutions sponsored by this program [4].

1. BCS-Oak Ridge National Laboratory

2. Pulse shape discrimination plastic scintillator-Oak Ridge National Laboratory

3. Helium-4 high pressure recoil scintillators-Idaho National Laboratory

4. Boron plates - Los Alamos National Laboratory 
5. EJ-309 liquid organic scintillators-University of Michigan

6. Stilbene scintillators-Lawrence Livermore National Laboratory

Each research team under this program has developed a conceptual collar based on the corresponding technologies and quantified its performance by simulating the collar using various test suites, including intact fuel assemblies, assemblies with partial defects, and assemblies with Gd rods. This report documents work on development of the collar using the BCS technology.

\subsection{ADVANTAGES AND DISADVANTAGES OF ${ }^{10}$ B-LINED COUNTERS FOR NEUTRON DETECTION}

Boron-10-lined cylindrical proportional counters (PCs) are among the oldest and most highly developed neutron detection technologies, as described by Rossi and Staub [5]. However, when ${ }^{3} \mathrm{He}$ gas became widely available, ${ }^{3} \mathrm{He}$-filled PCs quickly became the dominant approach to neutron detection because they were cost-effective, simple to make, and offered higher efficiency per tube. Recently the demand for ${ }^{3} \mathrm{He}$ has challenged the supply, costs have risen sharply, and there is a concern over the long-term supply. This has refocused attention on boron-lined PC approaches to providing general purpose safeguards solutions to neutron counting needs. Several important points need to be made about this technology. First, gasfilled PCs are inherently extremely reliable and extremely stable. These characteristics are exceedingly important in nuclear safeguards applications. Second, they can be operated with extremely high gammato-neutron discrimination, comparable or better than ${ }^{3} \mathrm{He}$, which most credible alternatives cannot match, as evidenced by the use of commercial detectors in reactor applications [6]. Third, the neutron capture process may be confidently simulated using standard transport code options [7]. This is important because in nondestructive assay there is usually the need to extend the calibration, most often performed using nonrepresentative items, and to calculate correction factors using computational methods. Multiple scattering, cross talk, and complicated pulse shape analysis do not need to be considered. In contrast to

${ }^{3} \mathrm{He}$-gas-filled PCs, ${ }^{10} \mathrm{~B}$-lined counters have a continuous energy deposition spectrum, and the threshold needed to discriminate gamma-rays results in lost efficiency.

A compromise between the boron layer thickness and detection threshold must be struck. Deposit thicknesses are normally limited to about $2 \mu \mathrm{m}$, and traditionally this limited achievable detection efficiency. Recently, however, several changes in thinking and practice have taken place so that the measurement penalty is not as great as it was once assumed to be. Advances in coating technology and manufacturing capability mean that large, robust areas of boron carbide can now be laid down in an automated and reproducible way.

\subsection{ADVANTAGES OF BORON-COATED STRAWS}

To overcome some of the disadvantages of ${ }^{10} \mathrm{~B}$ counters noted above, BCSs have recently been developed. By using small diameter straws with internal structure, the boron concentration per unit volume of the moderator has been increased considerably. An additional and crucial benefit is that the boron is distributed throughout the moderator more uniformly so that thermal neutrons can be absorbed at the point of thermalization, which reduces the system die-away time. For coincidence counting applications both efficiency and die-away time are important in governing system performance, so a BCS design does not have to match a standard ${ }^{3} \mathrm{He}$-based design on efficiency if it has a lower die-away time. These developments, coupled with the paradigm shift in the approach to neutronic design, have led to the realization that commercially available BCS detectors, the straw aspects of which are proven in the high energy physics community for image reconstruction, can provide viable and scalable ${ }^{3} \mathrm{He}$-free solutions for a wide range of safeguards and other applications. Houston-based Proportional Technologies, Inc. (PTI) is in the vanguard of those companies commercially exploiting the BCS technology [8]. A recent article reviewing neutron detectors for the interdiction and verification of special nuclear materials 
concludes that "small-diameter, boron-lined proportional tubes" are the most promising technology to replace ${ }^{3} \mathrm{He}$ detectors in portal monitors and other large-scale applications [9] [10]. We consider the technology to be mature so that commitment to build the proposed design presents a low engineering risk.

\subsection{A BCS-BASED HIGH-LEVEL NEUTRON COINCIDENCE COUNTER PROTOTYPE}

A full-scale, fully operational BCS-based prototype to replace the high-level neutron coincidence counter (HLNCC) was fabricated by PTI in 2014 [11] [12]. Figure 1 shows an overview of the prototype, sealed BCS detectors, and a cross-sectional view of the polyethylene body of the prototype with holes to accommodate the BCS detectors. This prototype has overall and cavity dimensions identical to those of the HLNCC-II, and weighs $135 \mathrm{lb}$, only $14 \mathrm{lb}$ heavier than its ${ }^{3} \mathrm{He}$-based counterpart. It is populated with 804 BCS detectors, each $4.4 \mathrm{~mm}$ in diameter, and lined with $2 \mu \mathrm{m}$ of vapor-deposited ${ }^{10} \mathrm{~B}_{4} \mathrm{C}\left({ }^{10} \mathrm{~B}\right.$-enriched boron carbide). These round straws are uniformly distributed in the polyethylene moderator. They are connected together in six groups of 134, each to read out with a custom-designed amplifier, fully compatible with a standard shift register. Despite the large number of straws, fabrication is facilitated by a series of BCS production enhancements and automations, including a high-yield, continuous operation, reel-to-reel boron coating process. At the same time, new sealing methods guarantee reliable operation over many decades, comparable to other sealed proportional counters [11].

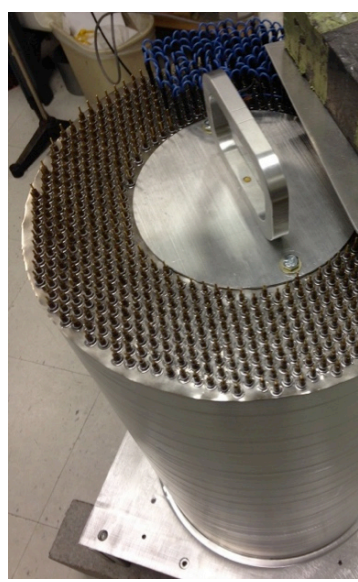

(a)

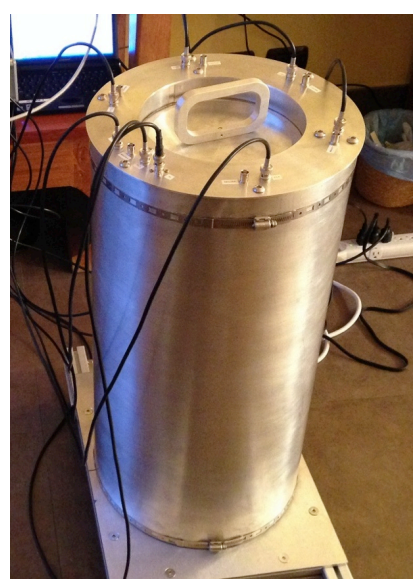

(b)

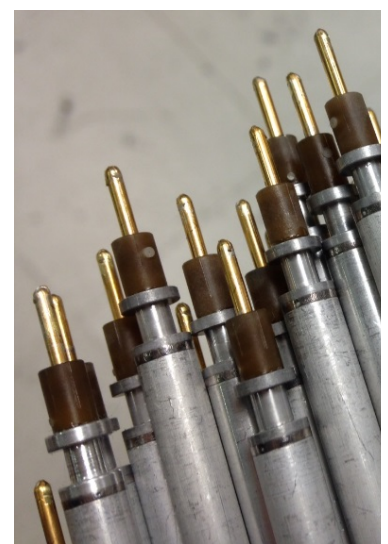

(c)

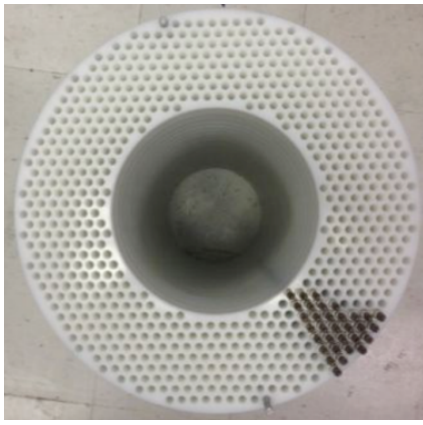

(d)

Figure 1. BCS-based HLNCC prototype (a, b), sealed BCS detectors (c), and the polyethylene body with holes to accommodate the BCS detectors (d) [11].

This BCS-based prototype was tested at the ${ }^{3} \mathrm{He}$ Alternatives for International Safeguards Workshop that took place at the Joint Research Centre in Ispra, Italy, in October 2014. Measurements of performance parameters collected at the workshop, including detection efficiency, $\varepsilon$, and neutron die-away time, $\tau$, are summarized in Table 1 [11]. The results demonstrate that the BCS-based counter achieves better performance than the standard ${ }^{3} \mathrm{He}$-based HLNCC, which was also tested at the workshop. The figure of merit (FOM), expressed as $\varepsilon^{2} / \tau$, was 7.11 , an improvement over the ${ }^{3} \mathrm{He}$-based counter (6.29) due to the $\sim 40 \%$ lower die-away time. The latter is attributed to the more uniform dispersion of neutron absorber throughout the moderator. Other counters based on different replacement technologies, including ${ }^{6} \mathrm{LiF}$ doped scintillators, and conventional boron-lined tubes did not reach the same level of performance (see Table 1), partly because of incomplete geometries. 
Table 1. Measured performance parameters for different replacement technologies [11]

\begin{tabular}{|c|c|c|c|c|}
\hline & ${ }^{3}$ He HLNCC & $\begin{array}{c}\text { BCS-based } \\
\text { HLNCC }\end{array}$ & $\begin{array}{c}{ }^{6} \text { LiF-based HLNCC } \\
\text { (1/4 populated) }\end{array}$ & $\begin{array}{c}\text { Boron-lined HLNCC } \\
\text { (not optimized) }\end{array}$ \\
\hline Efficiency $(\varepsilon)$ & $16.5 \%$ & $13.6 \%$ & $8.9 \%$ & $10.2 \%$ \\
\hline Die-away time $(\tau)$ & $43.3 \mu \mathrm{s}$ & $26 \mu s$ & $56 \mu \mathrm{s}$ & $65 \mu \mathrm{s}$ \\
\hline $\operatorname{FOM}\left(\varepsilon^{2} / \tau\right)$ & 6.29 & 7.11 & 1.41 & 1.60 \\
\hline
\end{tabular}

Acronyms: HLNCC = high-level neutron coincidence counter, $\mathrm{BCS}=$ boron-coated straw, and FOM = figure of merit.

Table 2 lists the costs for the items used in this BCS-based HLNCC prototype. As shown, labor accounts for more than $60 \%$ of the overall cost $(\$ 55 \mathrm{~K})$, which can be further reduced when the process is automated, especially in a scaled-up production. The cost of the boron coating, in the form of ${ }^{10} \mathrm{~B}_{4} \mathrm{C}$, is $\sim \$ 9 \mathrm{k}$ for this detector, accounting for $60 \%$ of the total materials cost.

Table 2. Costs for the BCS-based HLNCC [11]

\begin{tabular}{ll}
\multicolumn{1}{c}{ Item } & Cost \\
\hline Materials & $\$ 15,000$ \\
Labor & $\$ 35,000$ \\
Amplifiers $(5 \mathrm{x})$ & $\$ 5,000$ \\
TOTAL & $\mathbf{\$ 5 5 , 0 0 0}$ \\
\hline
\end{tabular}

Acronyms: BCS $=$ boron-coated straw and HLNCC $=$ high-level neutron coincidence counter.

In conclusion, a full-scale neutron coincidence counter based on the reliable, low-cost BCS detectors was shown to be capable of successfully replacing the standard ${ }^{3} \mathrm{He}$-based system in a compact geometry, and it is fully compatible with existing electronics and procedures. 


\section{CONCEPTUAL DESIGNS OF THE BCS-BASED COLLARS FOR UNCL REPLACEMENT}

\subsection{BASICS OF BCS DETECTORS}

Table 3 lists the main characteristics of the BCS detectors used in this project [13], including the materials and dimensions of each layer of the straw. Note that standard values for boron coating thickness and straw pitch are shown here, but they were varied in this work for optimal detector response. Figure 2 shows the basic design (round tube) and three advanced straw designs: six-point star, pie-6, and pie-12. The purpose of these advanced designs was to increase the internal wall areas, which are exposed to the fill gas inside the straws, for $\mathrm{B}_{4} \mathrm{C}$ coating while maintaining the same coating thickness. As a result, the total coating area has been increased by a factor of $1.4,2.0$, and 3.0 for the six-point star, pie-6, and pie-12 designs, respectively, compared with that of the basic design. A 12-point star (not shown here) design can increase the wall area by a factor of 2.0. PTI has fabricated these advanced straws and experimentally demonstrated that the improvement in neutron detection efficiency of these straws was nearly proportional to that of the coating areas [11]. For both the round and the star designs, $\mathrm{B}_{4} \mathrm{C}$ is first coated onto thin copper foils, formed into desired shapes, and then placed into aluminum gas tubes. PTI plans to concentrate on low-cost production of basic thick-walled round straws using a simple continuous drawing/welding technique to reduce production costs. The corrugated straws (e.g., star shaped) can be manufactured in a similar fashion by adding an extra step for forming the foil into desired shapes. To make the pie-shaped straws, the coated foil is placed over bar stock, and the resulting shapes are clamped together to form the septas and then rolled and inserted into the aluminum tube. This process can be automated as well.

Table 3. Main characteristics of BCS detectors [13]

\begin{tabular}{llccc}
\hline \multicolumn{1}{c}{ Item } & \multicolumn{1}{c}{ Material } & $\begin{array}{c}\text { Outer diameter } \\
(\mathbf{c m})\end{array}$ & $\begin{array}{c}\text { Thickness } \\
(\mathbf{c m})\end{array}$ & $\begin{array}{c}\text { Density } \\
\mathbf{( g / \mathbf { c m } ^ { \mathbf { 3 } } )}\end{array}$ \\
\hline Fill gas & $90 \%$ argon and $10 \% \mathrm{CO}_{2}$ & 0.4430 & - & $1.20 \mathrm{E}-3$ \\
Boron coating $^{a}$ & $\mathrm{~B}_{4} \mathrm{C}$ with ${ }^{10} \mathrm{~B}$ enriched to $96 \%$ & 0.4434 & $2.00 \mathrm{E}-04$ & 2.38 \\
Coating foil & copper & 0.4485 & $2.54 \mathrm{E}-03$ & 8.92 \\
Gas tube wall & aluminum & 0.5588 & $5.52 \mathrm{E}-02$ & 2.70 \\
Straw pitch $^{a}$ & $0.9144 \mathrm{~cm}$ & & & \\
\hline
\end{tabular}

${ }^{a}$ Standard values shown here; both the boron coating thickness and straw pitch were varied in this work for detector optimization.

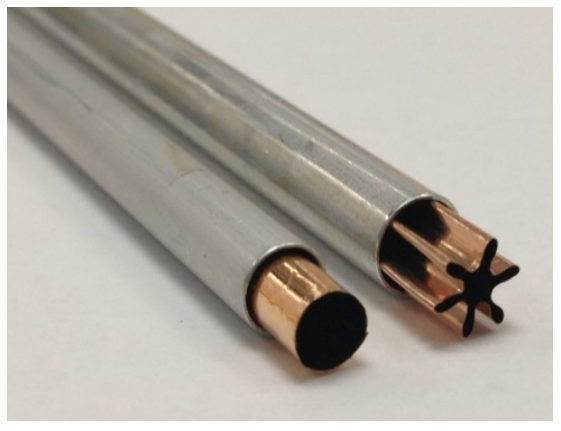

(a)

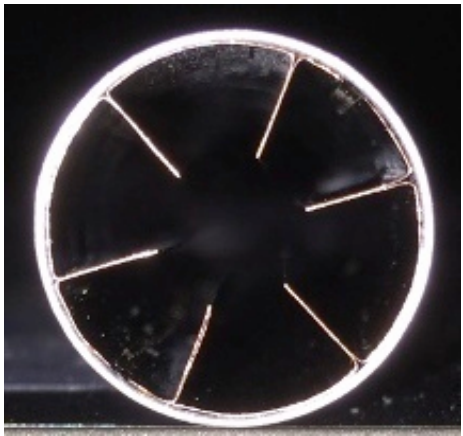

(b)

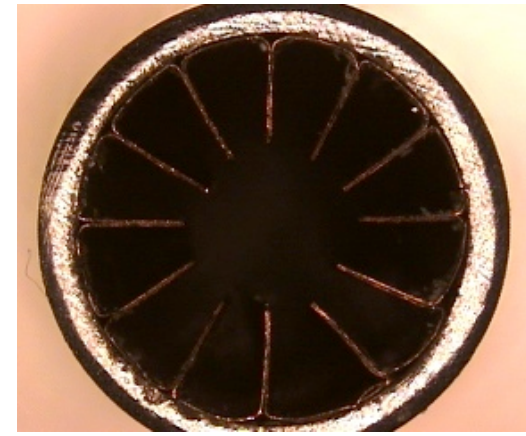

(c)

Figure 2. The basic straw design (round) and three advanced straw designs: (a) the basic straw design (left) and the (advanced) six-point star, (b) pie-6, and (c) pie-12. The six-point star, pie-6, and pie-12 increase the total boron coating area by a factor of 1.4, 2.0, and 3.0, respectively, compared with the basic design. 
When a neutron is absorbed in the $\mathrm{B}_{4} \mathrm{C}$ coating layer of the straws, it reacts primarily with the ${ }^{10} \mathrm{~B}$ atoms because ${ }^{10} \mathrm{~B}$ has a large neutron absorption cross section, orders-of-magnitude greater than that of ${ }^{11} \mathrm{~B}$ or carbon atoms. The straws are much more sensitive to thermal neutrons because ${ }^{10} \mathrm{~B}$ has a much higher cross section for thermal neutrons. The relevant reaction is shown here: ${ }^{10} \mathrm{~B}_{5}+{ }^{1} \mathrm{n}_{0} \rightarrow{ }^{7} \mathrm{Li}_{3}+{ }^{4} \mathrm{He}_{2}$. The lithium and $\alpha$ particles are emitted isotopically in opposite directions with kinetic energies of $1.47 \mathrm{MeV}$ and $0.84 \mathrm{MeV}$, respectively. For a $\mathrm{B}_{4} \mathrm{C}$ layer that is $1 \mu \mathrm{m}$ thick, one of the two charged particles escapes the wall $78 \%$ of the time and ionizes the gas contained within the straw, causing a neutron detection event that can be captured by the associated electronics [8]. The thicker the coating layer is, the higher the neutron absorption probability but the lower the probability for the lithium and $\alpha$ particles to escape the layer and deposit energy in the gas. The threshold is normally set at $73 \mathrm{keV}$ to reject the gamma pileups. Figure 3 shows the simulated probability of energy deposition in the gas by the lithium and $\alpha$ ions as a result of ${ }^{10} \mathrm{~B}$ neutron absorptions for various boron coating thicknesses. For energies above $1.2 \mathrm{MeV}$, the probabilities of depositing energies in that range are higher for straws with thinner boron coating layers. Figure 4 shows the electronic efficiency factor (EEF) of the BCS detectors as a function of coating thickness. EEF accounts for the probability of eventual neutron detection by the electronics for every neutron absorbed in the coating layer, and more details about EEF can be found in the appendix. This factor was calculated in this project using both analytical methods and Monte Carlo N-particle (MCNP) computer simulations (including considerations of charged particle energy deposition), and the results were nearly identical. With this factor, one only needs to tally the neutron absorption rates in the coating layer and multiply the rates by EEF to predict the neutron count rates, which is the approach adopted in this project.

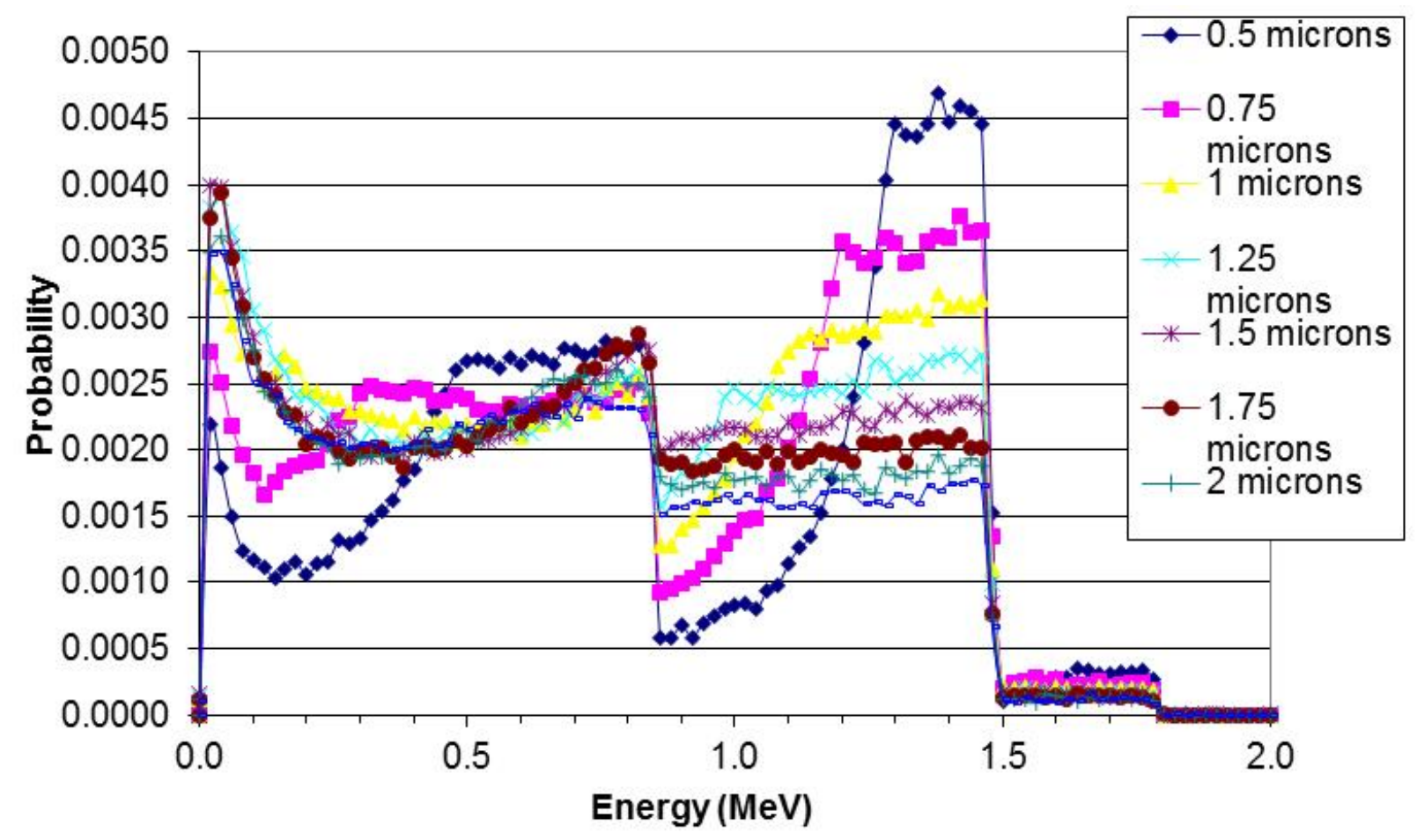

Figure 3. Probability of energy deposition with various boron coating layer thicknesses after a neutron absorption event takes place in the layer. 


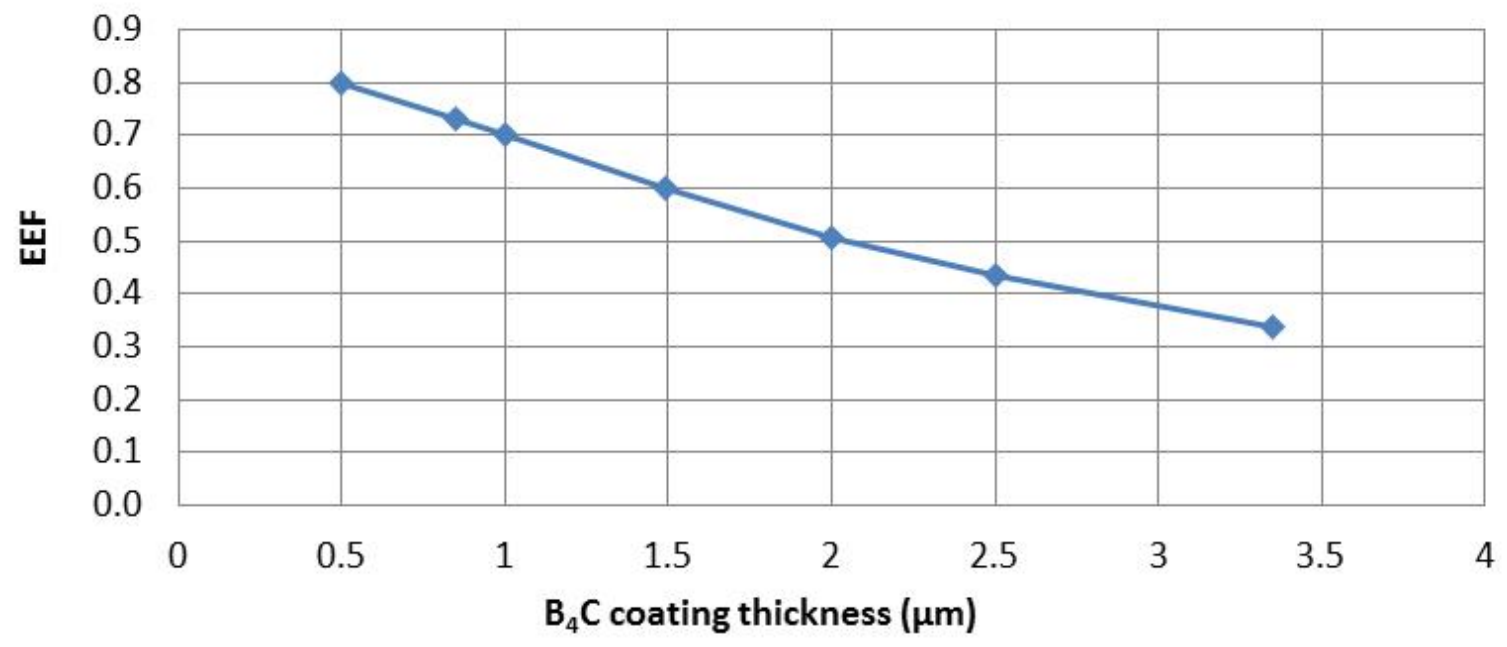

Figure 4. The electronic efficiency factor (EEF) for neutrons of the boron-coated-straw detector as a function of boron coating thickness.

\subsection{THE BASE MODEL OF THE BORON-COATED-STRAW COLLAR}

Figure 5 shows the conceptual design of the base model of the BCS collar, referred to as the "BCS base collar," on the left and a diagram of UNCL-II on the right for comparison. The BCS base collar has nearly identical outer dimensions to the UNCL-II. A $17 \times 17$ pressurized water reactor (PWR) assembly is also shown in the cavity of the BCS collar in the left figure. The bodies of the BCS collar and UNCL are made of high density polyethylene, including the block that holds the AmLi neutron source, although different colors are shown in the BCS model due to different material numberings used in the MCNP model. In the BCS base collar, 1,076 straws, shown as round green dots in Figure 5, are used as opposed to the $20{ }^{3} \mathrm{He}$ tubes used in UNCL-II. The outer diameter of the straws is $5.5 \mathrm{~mm}$, and the pitch between two neighboring straws is $9 \mathrm{~mm}$. Optimizations of this model are discussed in the following subsection.

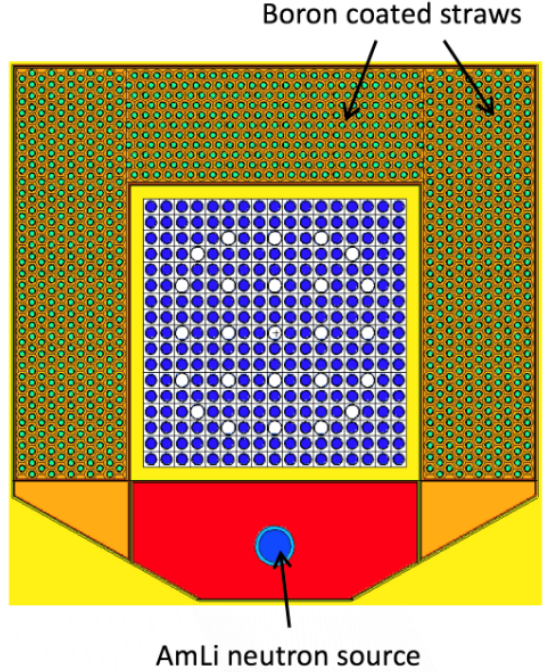

(a)

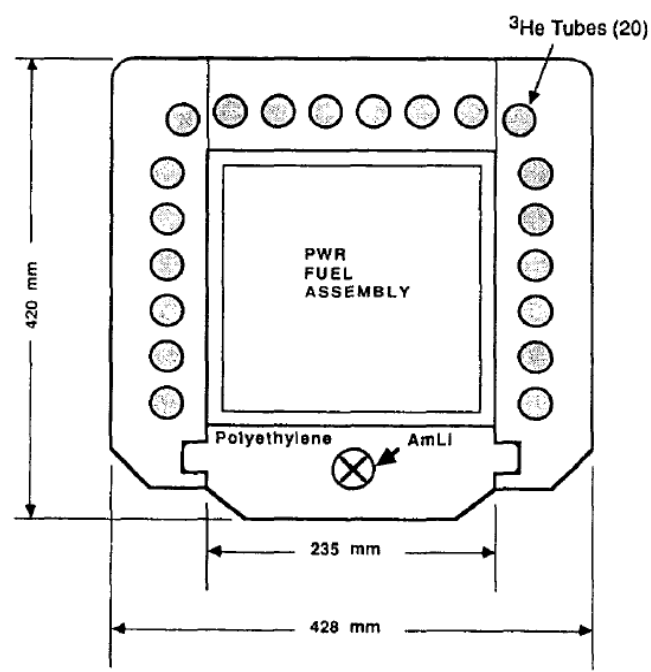

(b)

Figure 5. Base model BCS collar compared with the Uranium Neutron Coincidence Collar-II (UNCL-II): BCS base collar with a fuel assembly in the middle (a); configuration and dimensions of UNCL-II (b) [1]. 
This collar can be operated in active and passive interrogation modes in air with and without use of the AmLi source. In the passive mode, the inherent neutrons are emitted primarily from spontaneous fissions of the ${ }^{238} \mathrm{U}$ in the fresh fuel assembly being measured (a similar technique can be useful for Mixed Oxide fuel but not discussed further in this report). Because the measurement is performed in air, these neutrons, born with fast energies, are not moderated within the fuel assembly and thus induce only a small amount of fissions with the ${ }^{235} \mathrm{U}$ and ${ }^{238} \mathrm{U}$ atoms in the assembly. These neutrons travel through the fuel assembly and enter into the polyethylene, where they are moderated and then absorbed by the straws nearby, causing a passive neutron signal in the data acquisition system. Some of the moderated neutrons travel back into the fuel assemblies and cause additional fissions in the assembly, adding to the passive signal. In the active mode additional neutrons are emitted from the AmLi source, with the yield of $5 \times 10^{4} \mathrm{n} / \mathrm{s}$ moderated by the polyethylene in the source block, and enter into the fuel assembly, inducing additional fissions with the ${ }^{235} U$ and ${ }^{238} U$ atoms. Because the fission cross section of ${ }^{235} U$ for thermal neutrons is

orders-of-magnitude higher than that of ${ }^{238} \mathrm{U}$, the induced fissions are predominantly caused by ${ }^{235} \mathrm{U}$. The neutrons from induced fission, together with the inherent neutrons, cause an active signal in the collar's data acquisition system. By subtracting the passive signal from the active signal to exclude the contribution from ${ }^{238} \mathrm{U}$ to the active counts, the net signal can be obtained and is then used to determine the quantity of ${ }^{235} \mathrm{U}$ in the fuel assembly. Some of the neutrons directly from the AmLi source or from the background of the measurement facility (e.g., from a different fuel assembly far away) can also be detected by the detector; to separate out these neutrons, neutron coincidence counting is used for this collar, i.e., only neutrons from the same fission events, filtered by a shift register, are counted by the data acquisition system in both passive and active modes.

\subsection{THE "PLUS" MODEL OF THE BORON-COATED-STRAW COLLAR}

Figure 6 shows the plus model of the BCS collar, referred to as the "BCS plus collar," which is larger than the base model and incorporates several novel design features. Incidentally, these features would benefit ${ }^{3} \mathrm{He}$-based collars too. The width, length, and height of this model are 52,49 , and $50 \mathrm{~cm}$, respectively, compared with the 43,43 , and $52 \mathrm{~cm}$ of UNCL-II. The number of straws was increased from the 1,076 of the base model to 1,802 to increase the overall neutron detection efficiency. This BCS plus collar has been optimized to reduce the sensitivity to the Gd rods in the fuel, which is discussed in detail in a later subsection. The cadmium liners of the base model were replaced with gadolinium liners around the cavity in the plus model. A half cylindrical shell with top and bottom of stainless steel is added and placed behind the AmLi source to reflect the neutrons back to the interrogation target - the fuel assembly. Boron was also added into the polyethylene in the source block to reduce the number of neutrons traveling through those regions and then being detected by the straws. The coating thickness of the $\mathrm{B}_{4} \mathrm{C}$ in the straws was $1.5 \mu \mathrm{m}$. In the analysis of both the base collar and the plus collar, it was assumed that the total $\mathrm{B}_{4} \mathrm{C}$ coating area was doubled using the advanced straw designs, although only round straws are shown in corresponding figures. More discussion about this is included in Subsect. 2.5.

Table 4 summarizes the main characteristics of the BCS plus collar. The total weight of this collar is estimated to be less than $70 \mathrm{~kg}$. Like UNCL, this collar can be separated into four pieces, which makes it easier for the inspectors to handle. The overall cost of this collar is estimated to be $\sim$ US $\$ 100,000$, which was scaled from the costs of the HLNCC prototype with consideration for $\sim 30 \%$ extra costs due to the advanced straw designs used in this collar. The cost for the data acquisition system for this collar was not included in this estimate. 


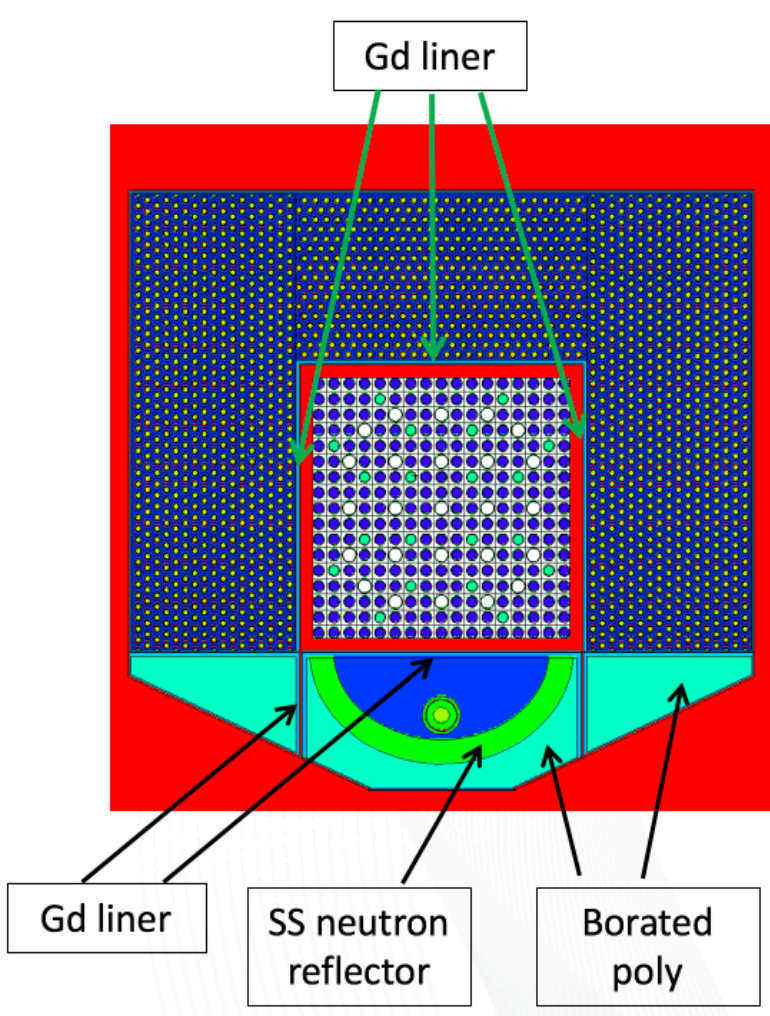

(a)

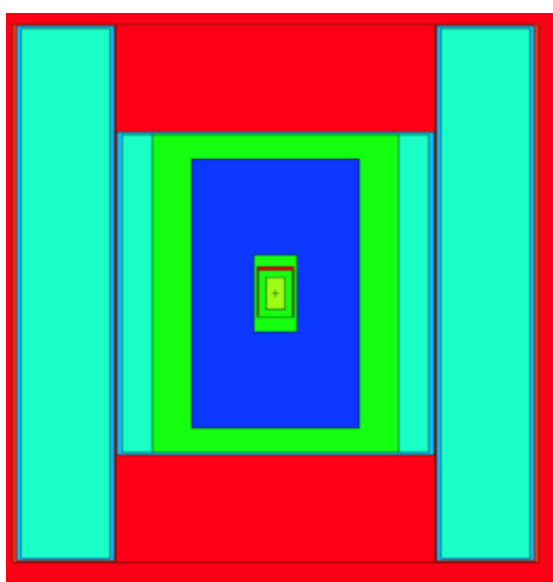

(b)

Figure 6. BCS plus collar: the XY cross-sectional view of the BCS plus collar (a); the XZ cross-sectional view of the plus collar with the Y plane cutting through the AmLi source (b). ("SS" stands for stainless steel.)

Table 4. Main characteristics of the BCS plus collar

\begin{tabular}{lc}
\hline \multicolumn{1}{c}{ Item } & Value \\
\hline Number of straws & 1,802 \\
Active straw length & $40 \mathrm{~cm}$ \\
Number of preamplifiers & 9 \\
$\mathrm{~B}_{4} \mathrm{C}$ coating thickness & $1.5 \mu \mathrm{m}$ (double-wall areas are assumed compared to round straws) \\
Outer dimensions & $52 \times 49 \times 50(\mathrm{~cm})$ \\
Total weight & $<70 \mathrm{~kg}$ (shared among four pieces) \\
Total cost & $\sim$ US $\$ 100 \mathrm{k}$ \\
Portability & cart portable \\
Safety concerns & None \\
Data acquisition & Compatible with IAEA neutron coincidence counting (INCC) \\
& software, shift-register or list mode. \\
Robustness & This system is robust, including the $\mathrm{B}_{4} \mathrm{C}$ coating. \\
& Reliable; tolerant to vibrations. Excellent $\mathrm{n} / \gamma$ discrimination and long- \\
& term stability. \\
\hline
\end{tabular}




\subsection{COUNTING STATISTICS}

For neutron coincidence counting, the relative standard deviation (RSD) of the doubles, $\sigma_{\mathrm{D}} / \mathrm{D}$, can be approximated by the following equation [14]:

$$
\frac{\sigma_{D}}{\mathrm{D}}=\sqrt{\frac{1}{D t}+\frac{2 S^{2} t_{g}}{D^{2} t}}
$$

where $S$ is singles count rate, $D$ is the doubles count rate, $\sigma_{D}$ is the standard deviation of $D, t_{g}$ is the gate width, and $t$ is the total counting time. When fast accidentals [15] are applied, the factor of " 2 " in front of " $S^{2} t_{g}$ " in this equation can be reduced to " 1 ." Because the singles rate is usually much higher than the doubles rate (by 2 orders of magnitude for this collar), the first term under the square root bracket can be omitted. With these two assumptions, Eq. (1) can be further simplified to

$$
\frac{\sigma_{D}}{\mathrm{D}} \approx \frac{S}{D} \sqrt{\frac{t_{g}}{t}}
$$

Equation (1) was used for the final results, and Eq. (2) was used for some of the optimization studies in this project.

\subsection{OPTIMIZATIONS FOR DETECTION EFFICIENTLY AND SOURCE-FUEL ASSEMBLY COUPLING}

To ensure the BCS collars have comparable or better performance than UNCL, including detection efficiency and counting precision, we performed studies to optimize the following design parameters: $\mathrm{B}_{4} \mathrm{C}$ coating thickness, straw pitch, and source location. As discussed in Subsect. 2.1, increasing the $\mathrm{B}_{4} \mathrm{C}$ thickness will increase the neutron absorption probability in the straws, but on the other hand it, will decrease the EEF; therefore, optimal thickness was sought to balance these two factors. The straw pitch dictates how many straws can be packed in the detector in given outer dimensions and also the amount of polyethylene between the neighboring straws. Longer pitches increase the neutron moderation and thus absorption probability in the straws, whereas shorter pitches reduce the die-away time, which is desirable for greater counting precision; therefore, the pitch needs to be optimized for better detector performance. The AmLi source location can be represented by the distance from the source to the center of the cavity (that hosts the fuel assembly). A shorter distance increases the solid angle for the source neutrons reaching the fuel assembly but reduces the moderation that is desirable to induce fissions in the ${ }^{235} \mathrm{U}$ of the fuel assembly. A longer distance increases the uniformity of the energy spectra among the source neutrons reaching the fuel assembly at different angles. Because the base model of the BCS collar was developed first, these optimizations were performed based on the base model and then applied to the plus model, which is considered appropriate due to the similarity between these two models.

Two FOMs were used to evaluate the different combinations of these parameters:

1. FOM $1, \varepsilon^{2} / \tau$, where $\varepsilon$ is the total efficiency of the detector, i.e., the probability of a source neutron being detected by the detector; $\tau$ is the die-away time of the detector.

2. FOM2, $\frac{D}{S \sqrt{t_{g}}}$, where $S$ is the singles count rate per source neutron and $D$ is the doubles count rate; $t_{g}$ is the gate width, which is usually set as 1.25 times $\tau$. 
FOM1 represents the balance between the efficiency and die-away time and was used to determine which combination of $\mathrm{B}_{4} \mathrm{C}$ coating thickness and straw pitch was optimal; FOM2 is basically the inverse of RSD with constant counting time $(t)$, as shown in Eq. (2), and it was used to determine which source distance was optimal. As previously mentioned, advanced straw designs were chosen for this collar to double the total coating area, but it is tedious to explicitly model each advanced straw (e.g., the stars or internal septas). As an alternative, round straws with doubled $\mathrm{B}_{4} \mathrm{C}$ coating thickness were modeled in the MCNP models, and thus the models contain the right amount of $\mathrm{B}_{4} \mathrm{C}$. This assumption would not introduce extra errors in the final results because we used two steps to calculate the neutron count rates: we first used the MCNP models to calculate the neutron absorption rates, including coincident absorption, in the $\mathrm{B}_{4} \mathrm{C}$ layer, and then multiplied the absorption rates by the EEF that corresponded to the intended coating thickness of the advanced straw. Because the MCNP models had the right amount of $\mathrm{B}_{4} \mathrm{C}$ in the right locations, the absorption rates were expected to be correctly calculated.

Table 5 lists the optimization results of the $\mathrm{B}_{4} \mathrm{C}$ coating thickness (before doubling) and straw pitch. Because the goal of this study was to optimize the inherent efficiency of the detector, the AmLi source was not simulated and a ${ }^{252} \mathrm{Cf}$ source was placed in the center of the cavity in the MCNP models. In this study, four different coating thicknesses, 1.25, 1.50, 2.0, and $2.25 \mu \mathrm{m}$, combined with four different pitches, $7.8,8.2,9.1$, and $10.1 \mathrm{~mm}$, were tested. To reduce the number of simulation cases, we first determined the optimal pitch by fixing the coating thickness at 2.25 but varying the pitch, as shown in cases $7-10$, and it was found that the $9.1 \mathrm{~mm}$ pitch gave the maximum FOM. Cases 2, 4, 6, and 9 all had the same $9.1 \mathrm{~mm}$ pitch but with different coating thicknesses, varying from 1.25 to $2.25 \mu \mathrm{m}$. The absorption rates (not shown) increased but EEF decreased to a greater extent, resulting in decreasing efficiency $(\varepsilon)$ with increasing coating thickness. In addition, the die-away time decreased with increasing coating thickness, which is expected because of the extra absorption due to the extra $\mathrm{B}_{4} \mathrm{C}$ in the system. As highlighted in yellow in this table, the combination of $1.5 \mu \mathrm{m}$ coating thickness and $9.1 \mathrm{~mm}$ yielded the maximum FOM, which formed the basis for the subsequent analysis in this project. The next step was to optimize the AmLi source location. Table 6 shows the optimization results for the source location. The distance between the AmLi source and the cavity center was varied from 15 to $17.5 \mathrm{~cm}$ to determine what distance offered the best source-fuel coupling and thus best precision. UNCL uses $16 \mathrm{~cm}$ and EFC uses $15.38 \mathrm{~cm}$ for the source distance. Singles and doubles rates both decrease with increasing distance, which is expected, mainly due to extra neutron absorption in the polyethylene along the way before the source neutrons reach the fuel assembly. The die-away time varied slightly among these cases. As highlighted in yellow, $17.0 \mathrm{~cm}$ was chosen for this collar because of its optimal FOM and higher count rates compared with the $17.5 \mathrm{~cm}$ case.

Table 7 shows a comparison of performance among the BCS collars and UNCL. Compared with the UNCL fast mode, the BCS base collar had lower efficiency but much shorter die-away time, yielding slightly higher FOM. The efficiency of the BCS plus collar was much improved, and its FOM is nearly 3 times that of UNCL. 
Table 5. Optimization of $\mathrm{B}_{4} \mathrm{C}$ coating thickness and straw pitch for the BCS collar

\begin{tabular}{|c|c|c|c|c|c|c|}
\hline Case ID & $\begin{array}{c}\mathrm{B}_{4} \mathrm{C} \text { coating } \\
\text { thickness } \\
(\mu \mathrm{m})\end{array}$ & EEF & $\begin{array}{l}\text { Pitch } \\
(\mathbf{m m})\end{array}$ & $\begin{array}{c}\text { Efficiency }(\varepsilon) \\
(\%)\end{array}$ & $\begin{array}{c}\text { Die-away time }(\tau) \\
(\mu \mathrm{s})\end{array}$ & $\begin{array}{c}\text { FOM1, } \varepsilon^{2} / \tau \\
\left(\%{ }^{2} / \mu \mathrm{s}\right)\end{array}$ \\
\hline 1 & 1.25 & 0.649 & 7.8 & 7.3 & 16.6 & 3.2 \\
\hline 2 & 1.25 & 0.649 & 9.1 & 9.4 & 22.3 & 4.0 \\
\hline 3 & 1.50 & 0.601 & 7.8 & 7.0 & 14.5 & 3.4 \\
\hline 4 & 1.50 & 0.601 & 9.1 & 9.1 & 19.7 & 4.2 \\
\hline 5 & 2.00 & 0.506 & 7.8 & 6.3 & 11.8 & 3.3 \\
\hline 6 & 2.00 & 0.506 & 9.1 & 8.1 & 16.2 & 4.0 \\
\hline 7 & 2.25 & 0.470 & 7.8 & 5.9 & 10.8 & 3.3 \\
\hline 8 & 2.25 & 0.470 & 8.2 & 6.5 & 12.0 & 3.6 \\
\hline 9 & 2.25 & 0.470 & 9.1 & 7.6 & 15.0 & 3.9 \\
\hline 10 & 2.25 & 0.470 & 10.1 & 8.1 & 17.8 & 3.7 \\
\hline
\end{tabular}

Table 6. Optimization of source location (distance between the AmLi source and the cavity center)

\begin{tabular}{|c|c|c|c|c|}
\hline $\begin{array}{c}\text { Source distance } \\
\text { from center } \\
(\mathbf{c m})\end{array}$ & Singles $(\boldsymbol{S})$ & Doubles $(\boldsymbol{D})$ & $\begin{array}{c}\text { Die-away time }(\boldsymbol{\tau}) \\
(\boldsymbol{\mu s})\end{array}$ & $\begin{array}{c}\text { FOM2 } \\
\left(\frac{\boldsymbol{D}}{S_{\sqrt{t_{g}}}}\right)\end{array}$ \\
\hline 15.00 & $5.96 \mathrm{E}-02$ & $6.84 \mathrm{E}-04$ & 25.28 & $1.03 \mathrm{E}-03$ \\
\hline 15.38 & $5.13 \mathrm{E}-02$ & $6.13 \mathrm{E}-04$ & 25.45 & $1.07 \mathrm{E}-03$ \\
\hline 16.00 & $3.97 \mathrm{E}-02$ & $5.08 \mathrm{E}-04$ & 25.71 & $1.15 \mathrm{E}-03$ \\
\hline 16.50 & $3.17 \mathrm{E}-02$ & $4.24 \mathrm{E}-04$ & 25.93 & $1.20 \mathrm{E}-03$ \\
\hline 17.00 & $2.51 \mathrm{E}-02$ & $3.47 \mathrm{E}-04$ & 25.46 & $1.24 \mathrm{E}-03$ \\
\hline 17.50 & $2.29 \mathrm{E}-02$ & $3.16 \mathrm{E}-04$ & 26.09 & $1.24 \mathrm{E}-03$ \\
\hline
\end{tabular}

Table 7. Comparison of performance among the boron-coated-straw and uranium-neutron-coincidence collars

\begin{tabular}{|c|c|c|c|c|c|c|}
\hline Model & Mode & Singles & EEF & $\begin{array}{c}\text { Efficiency }(\varepsilon) \\
(\%)\end{array}$ & $\begin{array}{c}\text { Die-away time }(\tau) \\
(\mu s)\end{array}$ & $\begin{array}{c}\text { FOM1, } \varepsilon^{2} / \tau \\
\left(\% \%^{2} / \mu s\right)\end{array}$ \\
\hline UNCL & thermal & 0.138 & 1.0 & 14 & 48.1 & 3.94 \\
\hline UNCL & fast & 0.124 & 1.0 & 12 & 44.0 & 3.48 \\
\hline $\begin{array}{l}\text { BCS base } \\
\text { collar }\end{array}$ & fast & 0.15 & 0.6 & 9 & 19.7 & 4.16 \\
\hline $\begin{array}{l}\text { BCS plus } \\
\text { collar }\end{array}$ & fast & 0.24 & 0.6 & 14 & 20.2 & 10.34 \\
\hline
\end{tabular}

Acronyms: $\mathrm{EEF}=$ electronic efficiency factor, $\mathrm{FOM}=$ figure of merit, $\mathrm{UNCL}=$ Uranium Neutron Coincidence Collar, and $\mathrm{BCS}=$ boron-coated-straw.

\subsection{OPTIMIZATIONS TO MINIMIZE GD-ROD SENSITIVITY}

As previously discussed, reducing sensitivity to the Gd rods of the fuel assembly is one of the two most important motivations to develop alternative instruments for UNCL replacement. In this project, a great amount of effort has been devoted to optimizing the collar to reduce the sensitivity to Gd rods. UNCL and EFC use a $1 \mathrm{~mm}$ thick cadmium liner to reduce the Gd-rod sensitivity, whereas the BCS collar uses a gadolinium liner instead. Figure 7 illustrates the neutron cross sections for ${ }^{155} \mathrm{Gd}$ absorption, ${ }^{235} \mathrm{U}$ fission, 
${ }^{112} \mathrm{Cd}$ absorption, and ${ }^{238} \mathrm{U}$ fission. Gadolinium- 155 and ${ }^{112} \mathrm{Cd}$ are the most isotopes with the greatest neutron absorbing capabilities, considering both abundance and cross section, for gadolinium and cadmium, respectively. For incident neutrons with energies lower than $0.03 \mathrm{eV}$, the absorption cross section of ${ }^{155} \mathrm{Gd}$ is about 2 orders of magnitude higher than the fission cross section of ${ }^{235} \mathrm{U}$, which in turn is about 2 orders of magnitude higher than the absorption cross section of ${ }^{112} \mathrm{Cd}$. For neutrons with energies above $200 \mathrm{eV}$, the ${ }^{235} \mathrm{U}$ fission cross section is comparable to the ${ }^{155} \mathrm{Gd}$ absorption cross section. When the source neutrons enter into the fuel assembly after being thermalized by the polyethylene in the source block, there is competition for neutrons among gadolinium isotopes from the Gd rods and the ${ }^{235} \mathrm{U}$ and ${ }^{238} \mathrm{U}$ of the fuel. Given the much larger absorption cross section of gadolinium than the fission cross section of ${ }^{235} \mathrm{U}$ and ${ }^{238} \mathrm{U}$, it appears inevitable that a significant fraction of neutrons will be absorbed by the Gd rods, to a degree depending on the total gadolinium loading in a given fuel assembly, unless the fraction of neutrons with energies below $0.03 \mathrm{eV}$ is minimized. A liner made of gadolinium would be efficient to remove neutrons within that energy range before the source neutrons reach the fuel. A gadolinium liner is more efficient than a cadmium liner in this regard by about 4 orders of magnitude, as shown in Figure 7. Therefore, a gadolinium liner was used around the cavity in the BCS collar, as shown in Figure 6.

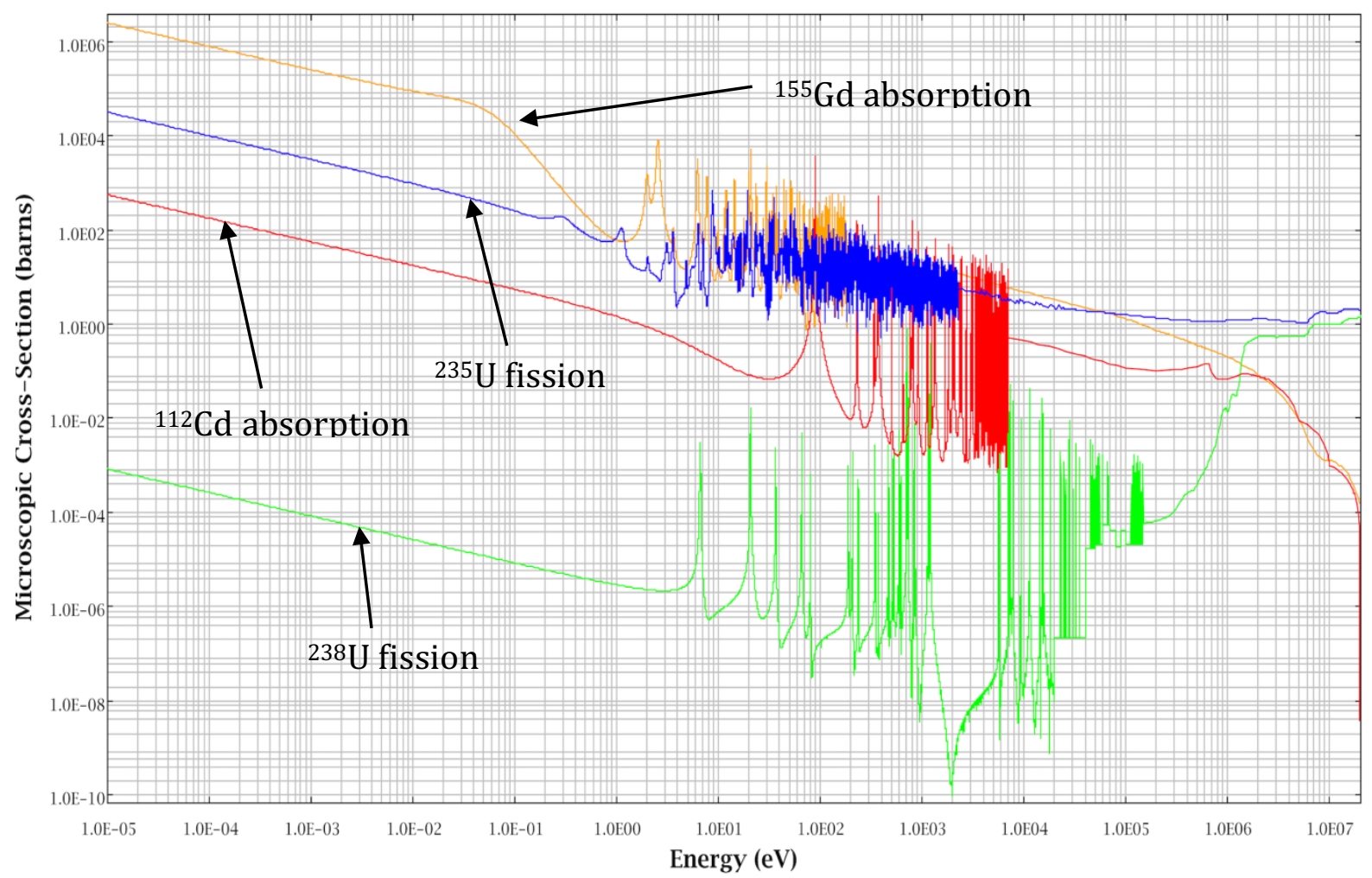

Figure 7. Microscopic neutron cross section (barns) for ${ }^{155} \mathrm{Gd}$ absorption, ${ }^{235} \mathrm{U}$ fission, ${ }^{112} \mathrm{Cd}$ absorption, and ${ }^{238} \mathrm{U}$ fission reactions as a function of incident neutron energy.

Figure 8 illustrates the energy spectra of the neutrons emitted by the AmLi source [16]. The source neutron population peaks $\sim 0.3 \mathrm{MeV}$, and the average energy is $\sim 0.5 \mathrm{MeV}$. The smaller peak $\sim 2 \mathrm{MeV}$ was due to the $(\alpha, n)$ neutrons from the trace amount of oxygen in the source. 


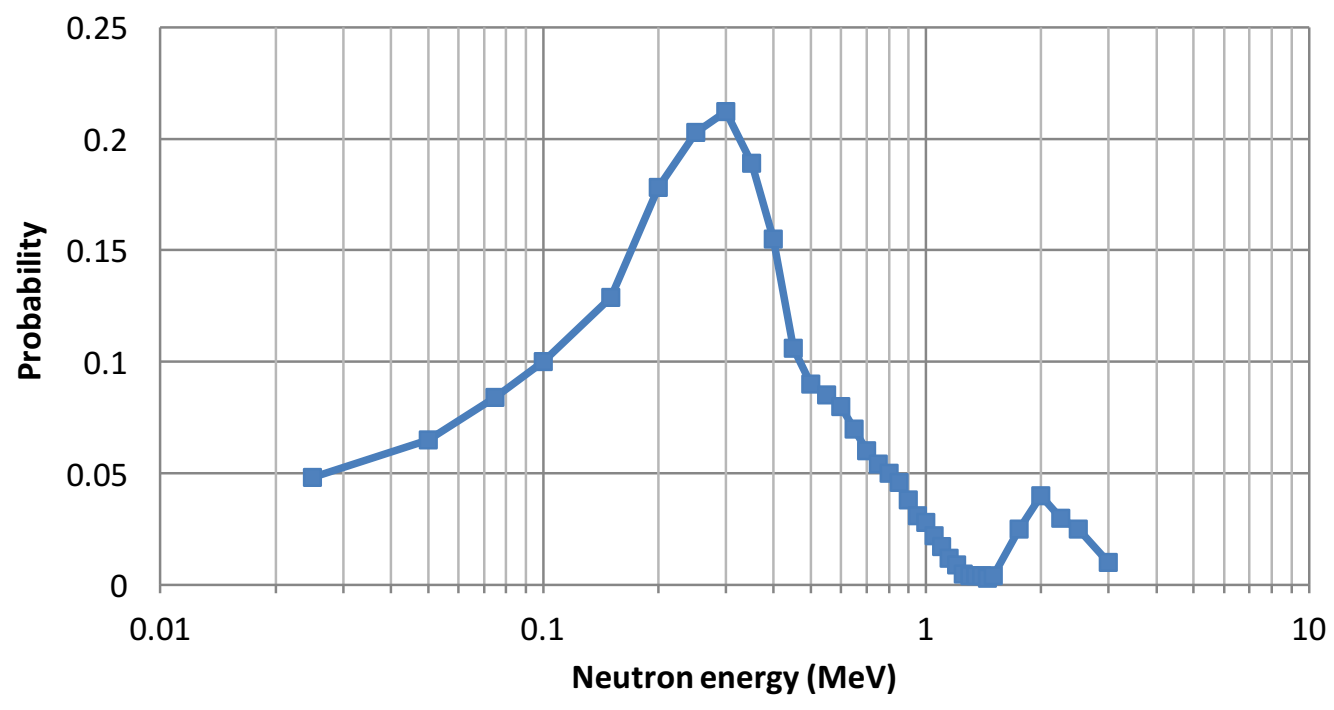

Figure 8. Neutron energy spectra of the AmLi source [16].

As shown in Figure 7 and Figure 8, the desired energy spectrum for neutrons entering the fuel assembly is different from that of the neutrons emitted by the AmLi source. To minimize the absorption rate of the Gd rods and maximize the fission rate of ${ }^{235} \mathrm{U}$, the desirable neutron energies are from $1 \times 10^{-5} \mathrm{MeV}$ to 0.1 $\mathrm{MeV}$, below the threshold energy of $\sim 2 \mathrm{MeV}$ for ${ }^{238} \mathrm{U}$ fission. On the other hand, the majority of the source neutrons have energies between $0.1 \mathrm{MeV}$ and $0.5 \mathrm{MeV}$. Given these differences, tailoring of spectra of source neutrons is needed. Several options for tailoring spectra in the source block have been explored during this project, including varying the thickness of the gadolinium liner, polyethylene densities, and neutron reflector materials. There are a number of approaches for this, and we chose a simplified approach. Figure 9 shows the MCNP model used for this study and the options explored. A box is placed immediately after the source block to tally the neutron flux emerging from the source block. Flux multiplication (FM) cards were used to calculate the reaction rates, including the fission rates of ${ }^{235} \mathrm{U}$ and ${ }^{238} \mathrm{U}$, and the absorption rates of gadolinium and cadmium. The FM cards can integrate the energydependent neutron flux in this box with the cross sections of these isotopes/elements and calculate the reaction rates. Different MCNP models were run to obtain the reaction rates for each combination of these varying parameters. 


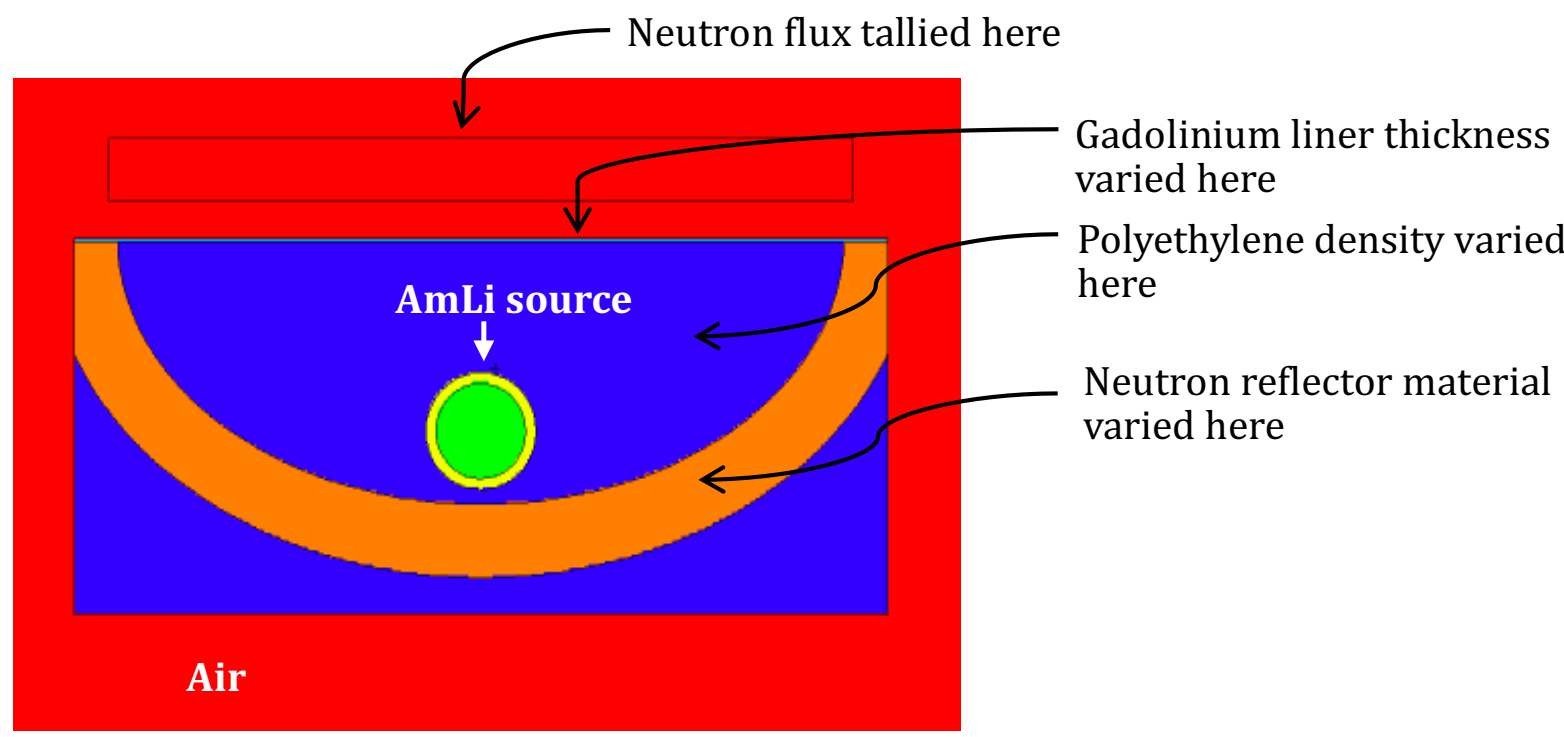

Figure 9. Parametric study of source block design to reduce sensitivity to Gd rods while increasing sensitivity to ${ }^{235} \mathrm{U}$.

Figure 10 shows both the ratio of the ${ }^{235} \mathrm{U}$ fission rate to the gadolinium absorption rate (the gadolinium ratio) and the ratio of the ${ }^{235} \mathrm{U}$ fission rate to the ${ }^{238} \mathrm{U}$ fission rate (the ${ }^{238} \mathrm{U}$ ratio) for each case calculated using the simplified model. The ${ }^{238} \mathrm{U}$ ratio is shown on the $\mathrm{Y}$-axis on the right. The higher value of the gadolinium ratio indicates lower sensitivity to $\mathrm{Gd}$ rods; the higher value of the ${ }^{238} \mathrm{U}$ ratio indicates higher signal to background ratio. Therefore, higher values of both ratios are desired. Table 8 shows the detailed results of this study. Note that the results in both this figure and this table use arbitrary units, which is not a problem for the purpose of this study because only relative comparisons between different cases are needed. The case name " 0.3 poly $+2 \mathrm{mmGd}+$ grph" represents the case that uses $0.3 \mathrm{~g} / \mathrm{cm}^{3}$ for the polyethylene density, $2 \mathrm{~mm}$ for the gadolinium thickness, and graphite for the reflector material. "Be" stands for beryllium here. For the cases that do not have reflector material in the names, there were no neutron reflectors (other than the polyethylene) included in the source block. The first case in Table 8 was not included in Figure 10 to reduce the range of data in the figure; in addition, this case was no longer considered due to its much poorer gadolinium ratio than the group. The main purpose of the first group of six cases was to assess the impact of gadolinium liner thickness and neutron reflector material on the ratio. As shown in the first group of five to six cases in both Figure 10 and Table 8, the gadolinium ratio increases with the thickness of the gadolinium liner, and replacing the cadmium liner with a gadolinium liner increases the gadolinium ratio by a factor of $\sim 2.2$ (comparing the " 0.3 poly $+2 \mathrm{mmCd}$ " against the " 0.3 poly $+2 \mathrm{mmGd"} \mathrm{case).} \mathrm{Although} \mathrm{the} \mathrm{reflector} \mathrm{materials} \mathrm{had} \mathrm{minimal} \mathrm{impacts} \mathrm{on} \mathrm{the} \mathrm{gadolinium} \mathrm{ratio,}$ they increased the ${ }^{238} \mathrm{U}$ ratio by $16 \%-28 \%$. As shown, beryllium is a more effective neutron reflector, but it is considered a health hazard, which probably prevents its use in this collar. The comparison among the second group of four cases shows that the gadolinium ratio decreases as a function of polyethylene density, but the ${ }^{238} \mathrm{U}$ ratio increases dramatically, which suggests that a compromise is probably needed to optimize both ratios at the same time. The results of the third group of three cases reinforced the previous findings that a thicker gadolinium liner significantly increased the gadolinium ratio but decreased the ${ }^{238} \mathrm{U}$ ratio, with the presence of a graphite reflector. More cases of using different combinations of these variables could have been studied but were not due to limited resources. Although the results of this optimization study are useful in illustrating the impacts of each considered parameters, we were not able to identify the set of optimal parameters for the final collar design due to the use of the simplified model and the complexity of the problem. Full collar models were used in the next optimization study, using this study as a guidance. 


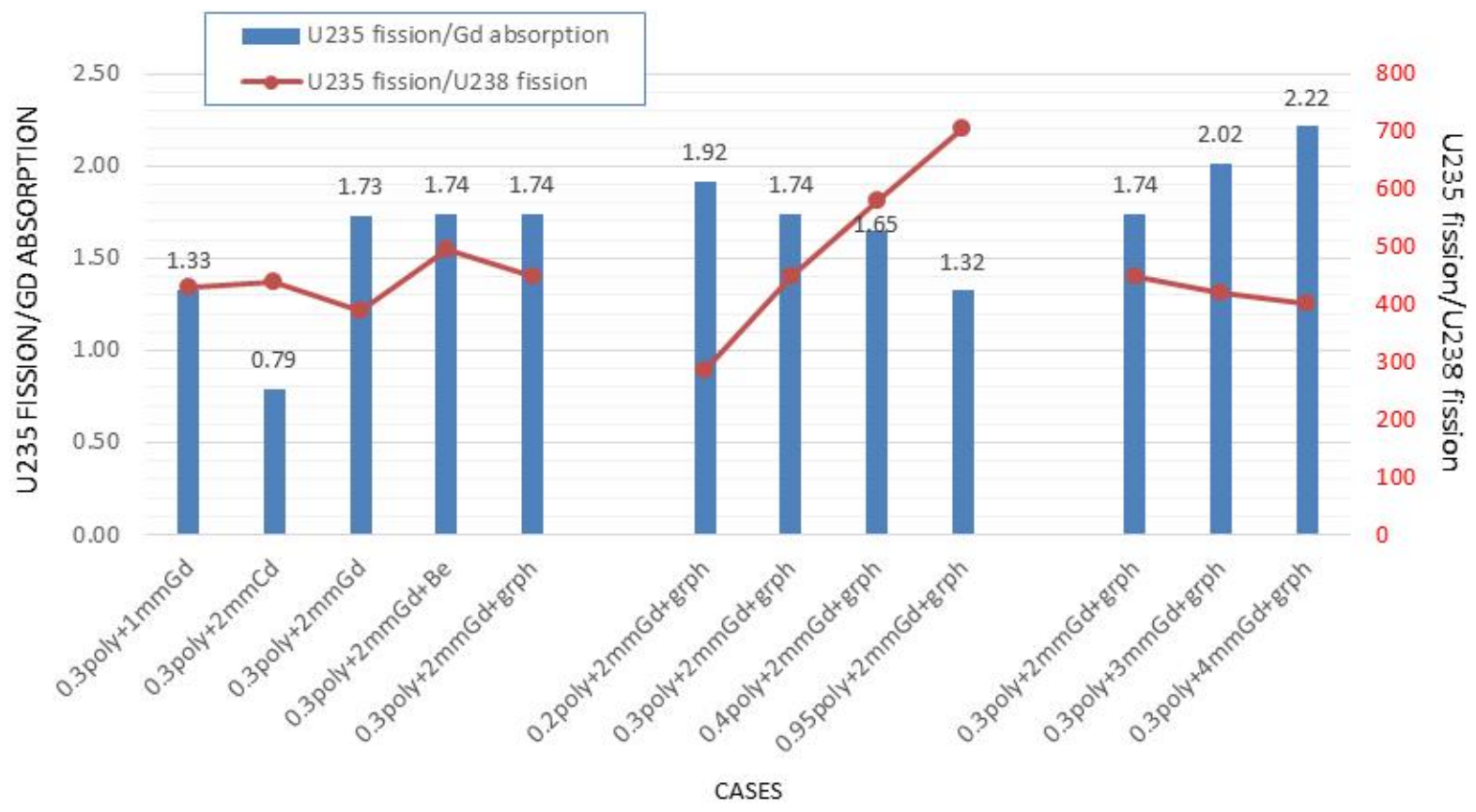

Figure 10. The ratio of ${ }^{235} U$ fission rate to the gadolinium absorption rate (left $Y$-axis) and the ratio of the ${ }^{235} U$ fission rate to the ${ }^{238} \mathrm{U}$ fission rate (right $\mathrm{Y}$-axis) for different combinations of polyethylene density, gadolinium liner thickness, and neutron reflector materials.

Table 8. Results of the source block optimization study

\begin{tabular}{lccccc}
\hline Case name & $\begin{array}{c}\text { Gd absorption } \\
\text { rate }\end{array}$ & $\begin{array}{c}{ }^{235} \mathbf{U} \text { fission } \\
\text { rate }\end{array}$ & $\begin{array}{c}{ }^{238} \mathbf{U} \text { fission } \\
\text { rate }\end{array}$ & $\begin{array}{c}{ }^{235} \mathbf{U} \text { fission } \\
\text { rate/Gd } \\
\text { absorption rate }\end{array}$ & $\begin{array}{c}{ }^{235} \mathbf{U} \text { fission } \\
\text { rate } /{ }^{238} \mathbf{U} \text { fission } \\
\text { rate }\end{array}$ \\
\hline 0.3 poly+0mmGd & $1.61 \mathrm{E}+00$ & $3.41 \mathrm{E}-02$ & $1.58 \mathrm{E}-05$ & 0.02 & $2.16 \mathrm{E}+03$ \\
0.3 poly+1mmGd & $5.07 \mathrm{E}-03$ & $6.72 \mathrm{E}-03$ & $1.56 \mathrm{E}-05$ & 1.33 & $4.31 \mathrm{E}+02$ \\
0.3 poly+2mmCd & $8.55 \mathrm{E}-03$ & $6.75 \mathrm{E}-03$ & $1.54 \mathrm{E}-05$ & 0.79 & $4.38 \mathrm{E}+02$ \\
0.3 poly+2mmGd & $3.46 \mathrm{E}-03$ & $5.99 \mathrm{E}-03$ & $1.54 \mathrm{E}-05$ & 1.73 & $3.89 \mathrm{E}+02$ \\
0.3 poly+2mmGd+Be & $4.57 \mathrm{E}-03$ & $7.94 \mathrm{E}-03$ & $1.60 \mathrm{E}-05$ & 1.74 & $4.96 \mathrm{E}+02$ \\
0.3 poly+2mmGd+grph & $4.21 \mathrm{E}-03$ & $7.33 \mathrm{E}-03$ & $1.63 \mathrm{E}-05$ & 1.74 & $4.50 \mathrm{E}+02$ \\
& & & & & \\
0.2 poly+2mmGd+grph & $2.75 \mathrm{E}-03$ & $5.28 \mathrm{E}-03$ & $1.85 \mathrm{E}-05$ & 1.92 & $2.85 \mathrm{E}+02$ \\
0.3 poly+2mmGd+grph & $4.21 \mathrm{E}-03$ & $7.33 \mathrm{E}-03$ & $1.63 \mathrm{E}-05$ & 1.74 & $4.50 \mathrm{E}+02$ \\
0.4 poly+2mmGd+grph & $5.02 \mathrm{E}-03$ & $8.30 \mathrm{E}-03$ & $1.43 \mathrm{E}-05$ & 1.65 & $5.80 \mathrm{E}+02$ \\
0.95 poly+2mmGd+grph & $3.74 \mathrm{E}-03$ & $4.95 \mathrm{E}-03$ & $7.01 \mathrm{E}-06$ & 1.32 & $7.06 \mathrm{E}+02$ \\
& & & & & \\
0.3 poly $+2 \mathrm{mmGd}+$ grph & $4.21 \mathrm{E}-03$ & $7.33 \mathrm{E}-03$ & $1.63 \mathrm{E}-05$ & 1.74 & $4.50 \mathrm{E}+02$ \\
0.3 poly+3mmGd+grph & $3.36 \mathrm{E}-03$ & $6.78 \mathrm{E}-03$ & $1.61 \mathrm{E}-05$ & 2.02 & $4.21 \mathrm{E}+02$ \\
0.3 poly+4mmGd+grph & $2.87 \mathrm{E}-03$ & $6.36 \mathrm{E}-03$ & $1.59 \mathrm{E}-05$ & 2.22 & $4.00 \mathrm{E}+02$ \\
\hline
\end{tabular}

In this study we also considered the optimization of counting precision using full detector models, as shown in Figure 6. For each model, six different assemblies were tested through simulation: three assemblies with different numbers of Gd rods (the gadolinium assemblies) and three corresponding nongadolinium assemblies, for which the gadolinium in the Gd rods was replaced by zirconium, a non- 
neutron-absorbing material. That way the uranium content was conserved in the two corresponding cases, the gadolinium and non-gadolinium assemblies. Each of the three gadolinium assemblies had 8, 20, and $24 \mathrm{Gd}$ rods, respectively, and the gadolinium weight percentage was $10 \%$ for all the Gd rods. These three cases are referred to as "Gd_rods_10\%_8x," "Gd_rods_10\%_20x," and "Gd_rods_10\%_24x," respectively. The Gd rods were evenly distributed throughout each assembly. The singles and doubles neutron count rates were both calculated using these models. The doubles rates of the gadolinium assemblies were compared with those of the corresponding non-gadolinium assemblies to determine the sensitivity to the Gd rods. The counting precisions were also calculated using Eq. (2). Different models were developed using different polyethylene densities in the source block, gadolinium liner thickness around three sides of the cavity of the collar (left, right, and top), and gadolinium liner thickness at the bottom side of the cavity (next to the source block). There could have been countless combinations of these parameters, not to mention the parameters not considered here. But the optimizations in the first step of this study provided guidance for this step. It was later discovered that the density for the marketavailable graphite varies from 1.6 to $1.85 \mathrm{~g} / \mathrm{cc}$, which is significantly lower than the theoretical values of 2.09 to $2.23 \mathrm{~g} / \mathrm{cc}$. The lower density of graphite reduces its effectiveness as a neutron reflector. Stainless steel was chosen for the neutron reflector instead in the final collar design because it has similar performance to the graphite of lower density but it was considered more practical. The results of a few examples are given below to demonstrate the exploration process that was taken to finalize the collar design optimization.

Table 9 shows the results for impacts of polyethylene density on Gd-rod sensitivity and counting precision of the collar. The sensitivity to Gd rods is expressed as percent doubles reduction, which means the relative reduction in doubles count rate (D) of the gadolinium case compared with the corresponding non-gadolinium case. The counting precision was indicated by the RSD of doubles for 10 min counting time, " $\sigma_{D} / D(\%)$ " in the table. The goal was to minimize both the Gd-rod sensitivity and the RSD. As shown in this table, the " $0.95 \mathrm{~g} / \mathrm{cc}$ " model had the lowest RSD and comparable Gd-rod sensitivity to the other two models. Furthermore, $0.95 \mathrm{~g} / \mathrm{cc}$ is the standard density for polyethylene; therefore $0.95 \mathrm{~g} / \mathrm{cc}$ was chosen for the final design. Similarly, Table 10 shows the impact of gadolinium liner thickness of the three sides of the cavity of the collar. The RSD is similar among the three models, but the $3 \mathrm{~mm}$ model had the lowest Gd-rod sensitivity on average. Therefore, a $3 \mathrm{~mm}$ gadolinium liner thickness was chosen for the three sides of the cavity in the final collar design.

Table 11 shows the impact of the thickness of the gadolinium liner on the bottom side of the cavity. Because this liner is right next to the AmLi source block and has greater impacts on the detector performance than the gadolinium liners on the other sides, the impact of its thickness was studied separately. As shown, the $6 \mathrm{~mm}$ model had lower gadolinium sensitivity than the $4 \mathrm{~mm}$ case, but with slightly higher RSD. Increasing the gadolinium thickness will further increase the RSD; therefore, $6 \mathrm{~mm}$ was chosen for the gadolinium liner on the bottom side. The results shown in Table 11 were based on the plus collar, and the doubles rates were $\sim 2.4$ times those from the base collar, shown in Table 10. In addition, the relative error was reduced by $40 \%$ for the plus collar. This collar can be further optimized depending upon whether the priority is low Gd-rod sensitivity or low RSD. Such choice should be made in discussion with the safeguards inspectorates to optimize the overall safeguards approach. 
Table 9. The impact of polyethylene density on Gd-rod sensitivity and counting precision of the boron-coatedstraw collar

\begin{tabular}{|c|cc|cc|cc|}
\hline \multirow{2}{*}{ Case identifier } & \multicolumn{3}{|c|}{ Density of polyethylene in the AmLi source block } \\
\cline { 2 - 7 } & \multicolumn{2}{|c|}{$\mathbf{0 . 3} \mathbf{g} / \mathbf{c c}$} & \multicolumn{2}{c|}{$\mathbf{0 . 5}$ g/cc } & \multicolumn{2}{c|}{$\mathbf{0 . 9 5}$ g/cc } \\
\cline { 2 - 7 } & $\begin{array}{c}\text { Doubles count rate } \\
(\mathbf{D}) \begin{array}{c}\text { reduction } \\
(\%)\end{array}\end{array}$ & $\begin{array}{c}\boldsymbol{\sigma}_{\mathbf{D}} / \mathbf{D} \\
\mathbf{( \% )}\end{array}$ & $\begin{array}{c}\text { D reduction } \\
(\%)\end{array}$ & $\begin{array}{c}\boldsymbol{\sigma}_{\mathbf{D}} / \mathbf{D} \\
(\%)\end{array}$ & $\begin{array}{c}\text { D reduction } \\
(\%)\end{array}$ & $\begin{array}{c}\boldsymbol{\sigma}_{\mathbf{D}} / \mathbf{D} \\
(\%)\end{array}$ \\
\hline Gd_rods_10\%_8x & -1.96 & 3.99 & -2.71 & 3.17 & 0.08 & 2.50 \\
Gd_rods_10\%_20x & -2.72 & 4.10 & -3.98 & 3.27 & -3.01 & 2.57 \\
Gd_rods_10\%_24x & -4.81 & 4.19 & -3.15 & 3.30 & -4.86 & 2.62 \\
\hline
\end{tabular}

Table 10. Impact of gadolinium liner thickness of three sides of the cavity of the collar

\begin{tabular}{|c|c|c|c|c|c|c|c|}
\hline \multirow{3}{*}{ Case identifier } & \multicolumn{7}{|c|}{ Thickness of gadolinium liner on three sides of the cavity (left, right, and top) } \\
\hline & \multicolumn{3}{|c|}{$2 \mathrm{~mm}$} & \multicolumn{2}{|c|}{$3 \mathrm{~mm}$} & \multicolumn{2}{|c|}{$5 \mathrm{~mm}$} \\
\hline & $\begin{array}{l}\text { Doubles } \\
\text { rate (D) }\end{array}$ & $\begin{array}{c}\text { D reduction } \\
(\%)\end{array}$ & $\begin{array}{c}\sigma_{D} / D \\
(\%)\end{array}$ & $\begin{array}{c}\text { D reduction } \\
(\%)\end{array}$ & $\begin{array}{c}\sigma_{\mathrm{D}} / \mathbf{D} \\
(\%)\end{array}$ & $\begin{array}{c}\text { D reduction } \\
(\%)\end{array}$ & $\begin{array}{l}\sigma_{\mathrm{D}} / \mathrm{D} \\
(\%)\end{array}$ \\
\hline Gd_rods_10\%_8x & $2.98 \mathrm{E}-04$ & 0.45 & 2.52 & 0.41 & 2.55 & -0.05 & 2.56 \\
\hline Gd_rods_10\%_20x & $2.83 \mathrm{E}-04$ & -3.02 & 2.63 & -1.91 & 2.64 & -2.39 & 2.64 \\
\hline Gd_rods_10\%_24x & $2.80 \mathrm{E}-04$ & -4.16 & 2.66 & -4.18 & 2.69 & -4.44 & 2.68 \\
\hline
\end{tabular}

Table 11. Impact of gadolinium liner thickness of the bottom side of the cavity of the collar

\begin{tabular}{|c|c|c|c|c|c|}
\hline \multirow[b]{3}{*}{ Case identifier } & \multicolumn{5}{|c|}{ Thickness of gadolinium liner on the bottom side of the cavity } \\
\hline & \multicolumn{2}{|l|}{$4 \mathrm{~mm}$} & \multicolumn{3}{|c|}{$6 \mathrm{~mm}$} \\
\hline & $\begin{array}{c}\text { Doubles rate }(\mathrm{D}) \\
\text { reduction } \\
(\%)\end{array}$ & $\begin{array}{c}\sigma_{\mathrm{D}} / \mathbf{D} \\
(\%)\end{array}$ & $\mathbf{D}$ & $\begin{array}{c}\text { D reduction } \\
(\%)\end{array}$ & $\begin{array}{c}\sigma_{\mathrm{D}} / \mathbf{D} \\
(\%)\end{array}$ \\
\hline Gd_rods_10\%_8x & -1.39 & 1.41 & $7.12 \mathrm{E}-04$ & -1.73 & 1.53 \\
\hline Gd_rods_10\%_20x & -2.88 & 1.45 & $6.86 \mathrm{E}-04$ & -2.75 & 1.58 \\
\hline Gd_rods_10\%_24x & -5.61 & 1.47 & $6.83 \mathrm{E}-04$ & -4.14 & 1.58 \\
\hline
\end{tabular}




\section{TEST RESULTS OF THE BORON-COATED STRAW PLUS COLLAR}

A series of test problems were provided to this project [4], and the BCS collars were tested against these problems. Given the much better performance offered by the BCS plus collar (in comparison to the base collar), only results for the plus collar are reported here. MCNP6.1 was used for these calculations [17]. For most cases, 100 million particle histories were used, which yields a statistical uncertainty rate less than $1 \%$ for the doubles rate. A universal FMULT card with the choice of Lawrence Livermore National Laboratory library, for choosing the appropriate neutron multiplicities for the actinides important to this collar, was used for all cases [17]. Some of the UNCL results provided by the sponsor were also included in this report for comparison. All results were based on the fast mode of this BCS plus collar and UNCL unless it is otherwise indicated.

\subsection{CALIBRATION CURVES}

To establish the calibration curves for the plus collar, each of the eight selected $17 \times 17$ fuel assemblies was virtually inserted into the cavity of the collar, and the count rates were simulated accordingly in both fast and thermal modes. For the thermal mode, the gadolinium liners of the collar, as shown in Figure 6, were removed. The ${ }^{235} \mathrm{U}$ enrichment in these assemblies was varied to represent a linear density (LD) of ${ }^{235} \mathrm{U}$ from $15 \mathrm{~g} / \mathrm{cm}$ to $65 \mathrm{~g} / \mathrm{cm}$. The gate width was set as 25 and $32 \mu \mathrm{s}$, with pre-day at 2 and $3 \mu \mathrm{s}$ for the fast and thermal modes, respectively. Figure 11 shows the calibration curve for the fast mode of the BCS plus collar compared with that of UNCL. The calibration function for this collar is also shown in the figure. The calibration curve for the plus collar was nearly identical to that of UNCL, which is encouraging because UNCL has demonstrated in the field over the last couple decades that it has sufficient sensitivity to discern different enrichments among the fuel assemblies under safeguards.

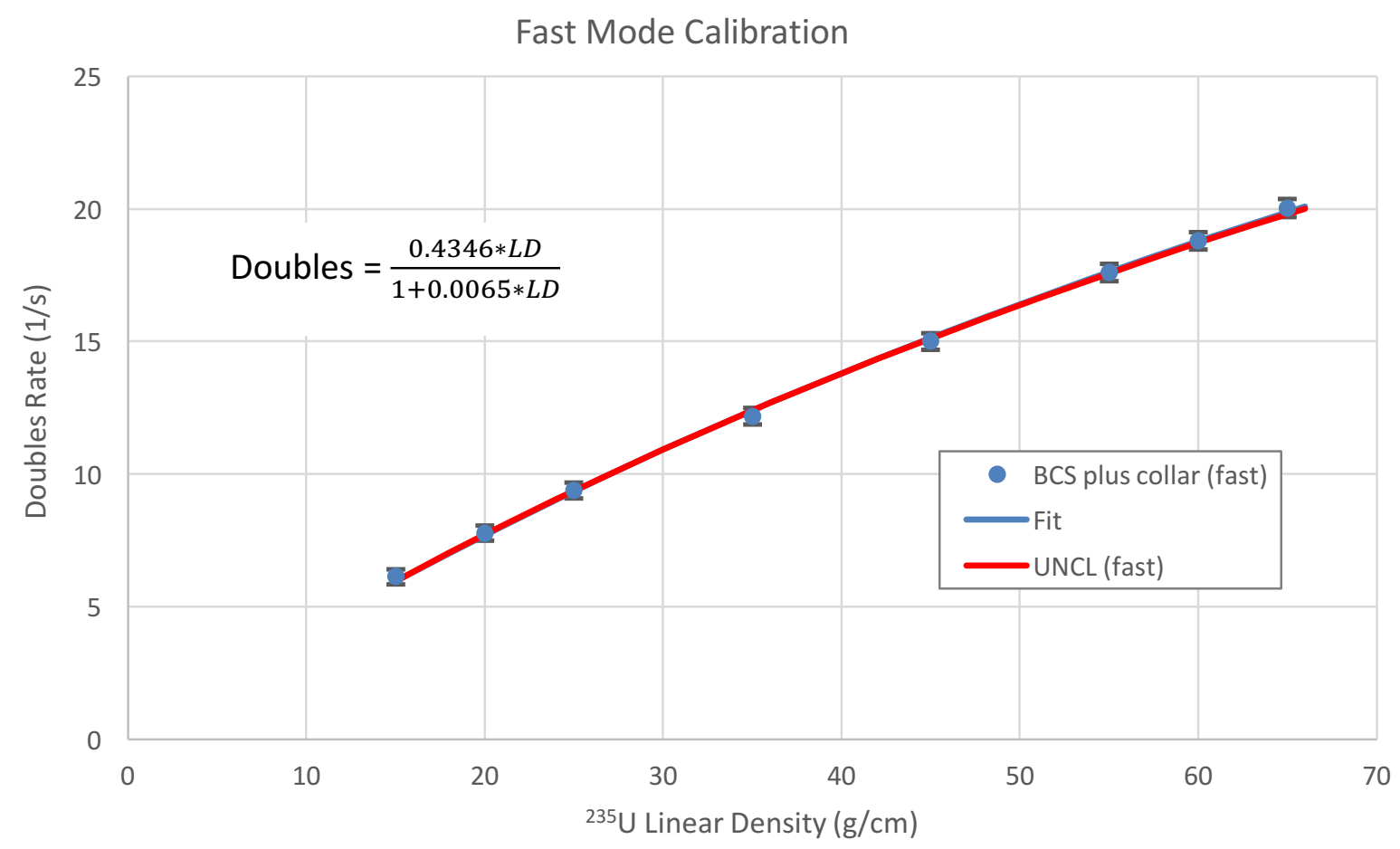

Figure 11. Calibration curve for the fast mode of the BCS plus collar compared with that of UNCL.

Table 12 shows the singles rates, doubles rates, and RSD of doubles (for 10 min counting time) of the $\mathrm{BCS}$ plus collar as a function of ${ }^{235} \mathrm{U}$ liner density in these tested fuel assemblies. As expected, the count 
rates increase and RSD decreases as a function of ${ }^{235} \mathrm{U}$ liner density. As discussed in the previous section, the plus collar uses 3-mm-thick gadolinium liners on three sides of the cavity and a 6-mm-thick gadolinium liner on the bottom side to reduce sensitivity to Gd rods, whereas UNCL uses a cadmium liner, only $1 \mathrm{~mm}$ thick, on all four sides of the cavity. The neutron count rates were much suppressed in the plus collar due to its use of thicker and more efficient neutron absorbing materials than UNCL. If the end user of this collar places higher priorities on goals other than low Gd-rod sensitivity, this collar can be modified accordingly to meet such goals.

\begin{tabular}{|c|c|c|c|}
\hline $\begin{array}{c}{ }^{235} \mathrm{U} \mathrm{LD}^{a} \\
(\mathrm{~g} / \mathrm{cm})\end{array}$ & $\begin{array}{c}\text { Singles } \\
(1 / \mathbf{s})\end{array}$ & $\begin{array}{c}\text { Doubles (D) } \\
(1 / \mathbf{s})\end{array}$ & $\begin{array}{l}\sigma_{\mathrm{D}} / \mathrm{D} \\
(\%)\end{array}$ \\
\hline 15.0 & 918.1 & 6.13 & 4.6 \\
\hline 20.0 & 926.3 & 7.77 & 3.7 \\
\hline 25.0 & 932.6 & 9.39 & 3.2 \\
\hline 35.0 & 947.6 & 12.18 & 2.5 \\
\hline 45.0 & 959.1 & 15.00 & 2.1 \\
\hline 55.0 & 972.7 & 17.61 & 1.9 \\
\hline 60.0 & 977.6 & 18.79 & 1.8 \\
\hline 65.0 & 983.1 & 20.03 & 1.7 \\
\hline
\end{tabular}

${ }^{a} \mathrm{LD}=$ linear density.

Figure 12 illustrates the calibration curve for the thermal mode of this collar, and Table 13 shows the count rates and RSD for the thermal mode. With the gadolinium or cadmium liners removed in both detectors for the thermal mode, this plus collar has $\sim 40 \%$ higher doubles count rates than UNCL, demonstrating the higher efficiency in this collar. RSD is much lower than that of the fast mode due to the higher count rates. 


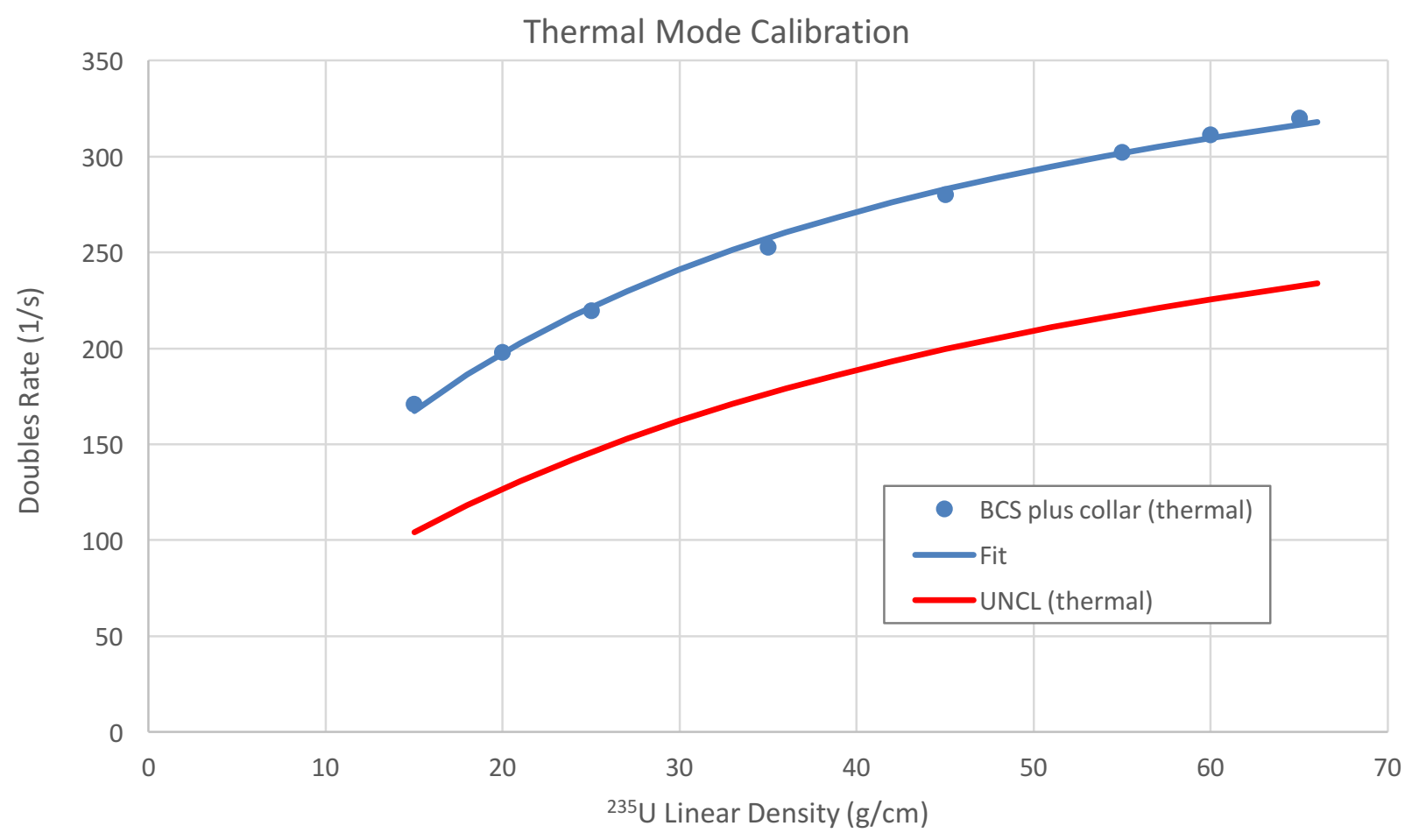

Figure 12. Calibration curve for the thermal mode of the BCS plus collar compared with that of UNCL.

Table 13. Calculated Singles rates, Doubles rates, and RSD (for 10 min counting time) of the BCS plus collar (thermal mode) as a function of ${ }^{235} \mathrm{U}$ liner density $(\mathrm{g} / \mathrm{cm})$ in the tested 1717 fresh fuel assemblies

\begin{tabular}{cccc}
\hline $\begin{array}{c}{ }^{235} \mathbf{U ~ L D}^{a} \\
(\mathbf{g} / \mathbf{c m})\end{array}$ & $\begin{array}{c}\text { Singles } \\
(\mathbf{1} / \mathbf{s})\end{array}$ & $\begin{array}{c}\text { Doubles } \\
(\mathbf{1} / \mathbf{s})\end{array}$ & $\begin{array}{c}\boldsymbol{\sigma}_{\mathbf{D}} / \mathbf{D} \\
\mathbf{( \% )}\end{array}$ \\
\hline 15.0 & 2631.1 & 171.0 & 0.59 \\
20.0 & 2738.8 & 198.0 & 0.54 \\
25.0 & 2821.1 & 219.8 & 0.50 \\
35.0 & 2935.6 & 252.6 & 0.46 \\
45.0 & 3011.3 & 280.0 & 0.43 \\
55.0 & 3069.8 & 302.1 & 0.41 \\
60.0 & 3094.5 & 311.5 & 0.40 \\
65.0 & 3115.2 & 320.0 & 0.39 \\
\hline
\end{tabular}

${ }^{a} \mathrm{LD}=$ linear density.

\subsection{TEST WITH UNPOISONED INTACT FUEL ASSEMBLIES}

In this test, 12 intact fuel assemblies were simulated with the plus collar. This set of fuel assemblies does not have any burnable poisons, but the assemblies are in four different lattice sizes: $14 \times 14,15 \times 15,16$ $\times 16$, and $17 \times 17$. These assemblies also have different ${ }^{235} \mathrm{U}$ enrichments and fuel rod dimensions, and 
some of them have nonuniform enrichments among the fuel rods across the assembly. Each of these assemblies was virtually placed in the cavity of this collar and MCNP simulations were performed to calculate the doubles rates in fast mode of this collar, which was used to infer the ${ }^{235} \mathrm{U}$ LD using the calibration function shown in Figure 11 that was based on the $17 \times 17$ fuel assemblies. The inferred ${ }^{235} U$ LD was then compared to the true ${ }^{235} \mathrm{U}$ LD to calculate the relative mass defect, which indicates how close the detector can measure the amount of ${ }^{235} \mathrm{U}$ in a particular assembly. In this case the true ${ }^{235} \mathrm{U} \mathrm{LD}$ can be calculated from the provided assembly models, whereas in a realistic safeguards inspection the densities are provided in the operator declaration.

Figure 13 depicts the relative mass defect for each of the 12 tested assemblies for both the plus collar and UNCL. The error bars on both figures represent the RSD of 30 min counting time with a $2 \%$ systematic uncertainty included. On average this collar had smaller mass defects than UNCL, which means this collar has higher tolerance to assemblies of different designs. The $14 \times 14$ and $16 \times 16$ assemblies had larger mass defects than the $15 \times 15$ and $17 \times 17$ assemblies. The calibration functions used in this calculation were based on $17 \times 17$ assemblies; typically corrections are made in safeguards practices to account for the differences in assembly designs, although such corrections were not made here since the goal was to make a worst-case comparison. 


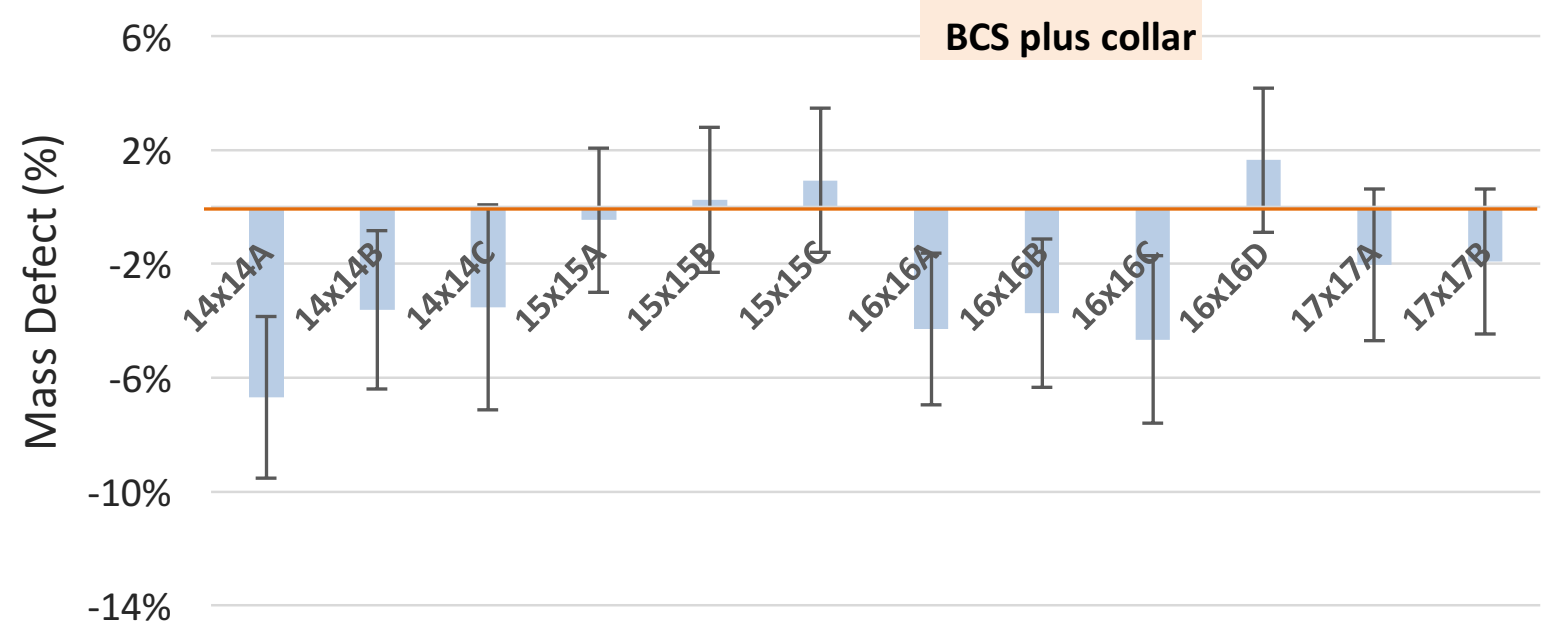

(a)

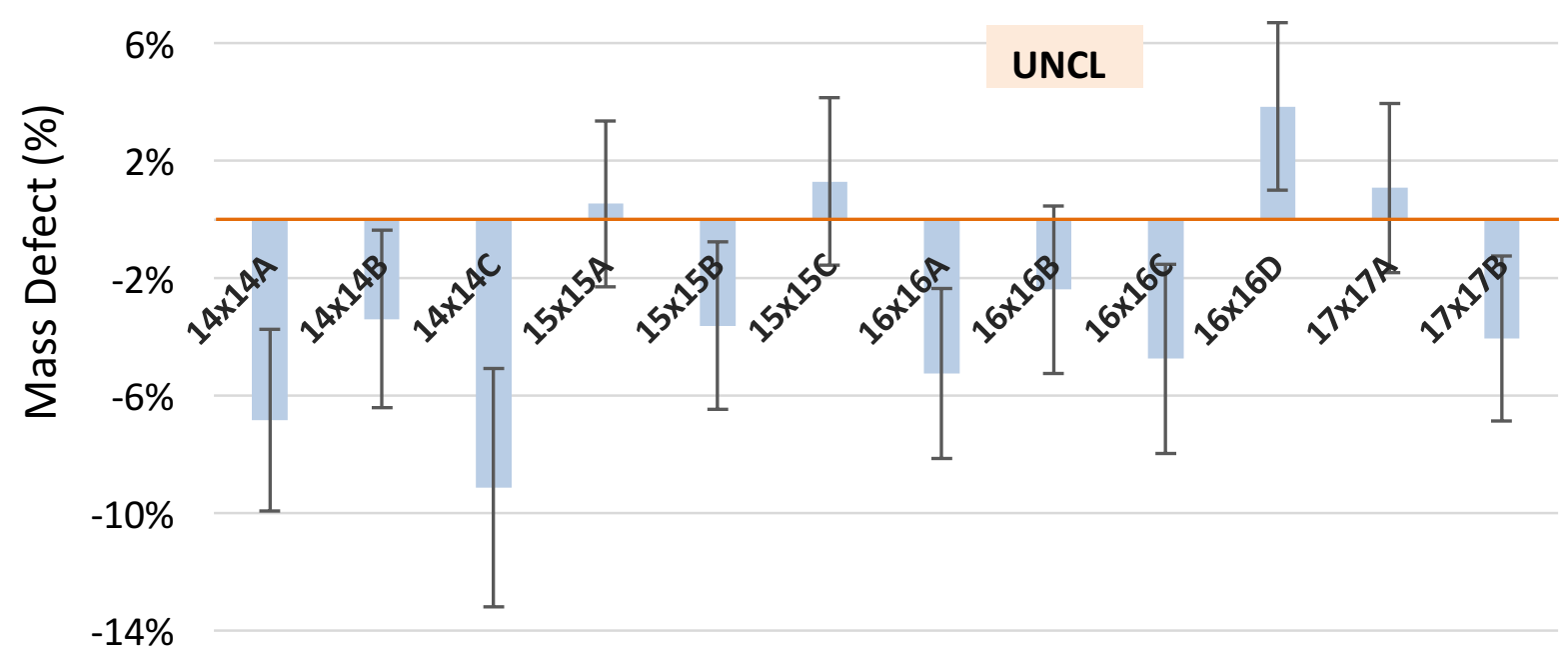

(b)

Figure 13. The relative mass defects of 12 simulated unpoisoned intact fuel assemblies for the BCS plus collar (a) and UNCL (b).

\subsection{PARTIAL DEFECT TEST}

Partial defect means one or more fuel rods being removed or substituted from a fuel assembly under safeguards. For this test, six different cases were simulated for this collar. The first case represents the intact $17 \times 17$ fuel assembly, and for the other five cases different numbers of fuel rods were replaced by rods filled with depleted uranium (DU) $(8,16,24,32$, and 40), as shown in Figure 14. The substitutions were evenly distributed across the assemblies, making it more challenging to detect. The count rates were simulated using the plus collar for each of the five assemblies with partial defects. The simulated doubles rates were used to infer the ${ }^{235} \mathrm{U} \mathrm{LD}$ in the corresponding assemblies using the calibration function, which was then compared with that of the intact fuel assembly to calculate the relative mass defect. 

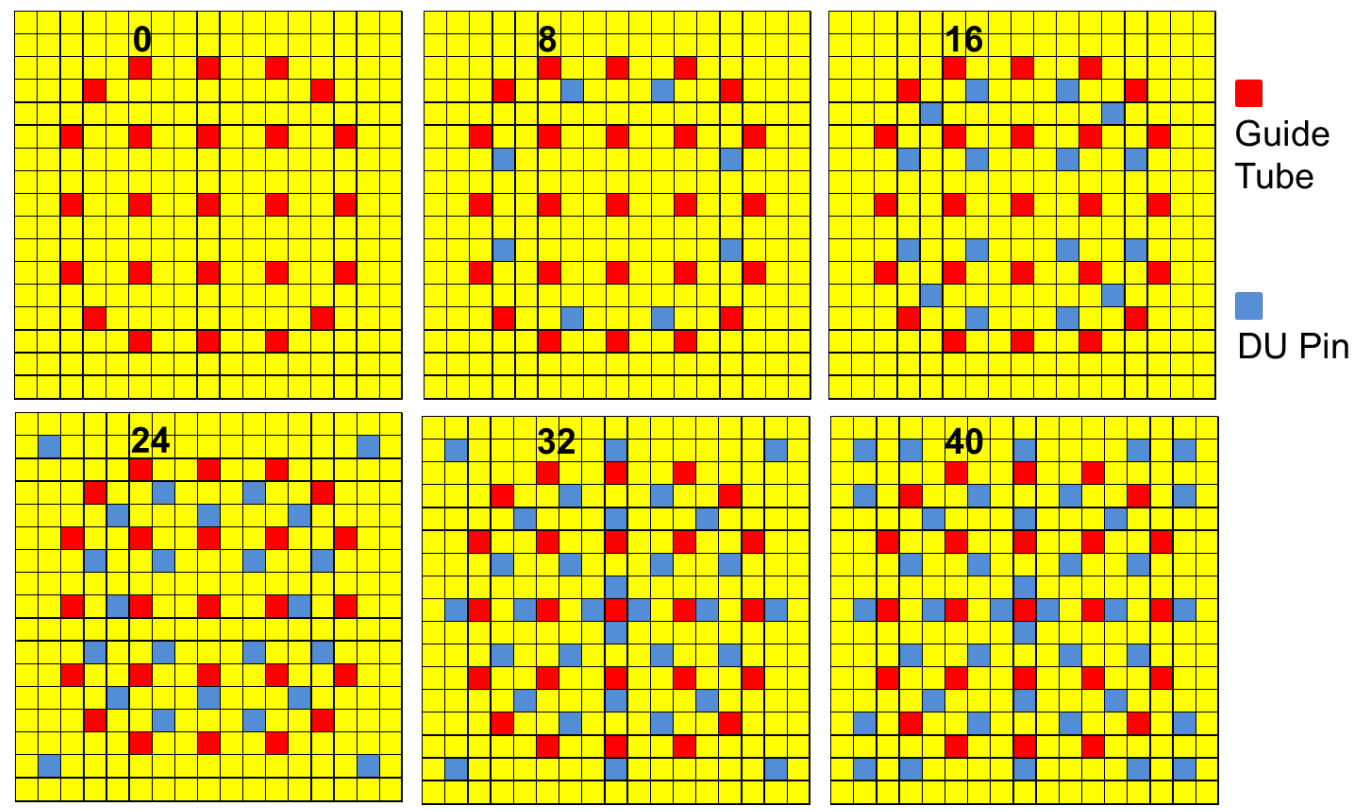

Figure 14. The assemblies for the partial defect test.("DU" = depleted uranium.)

Figure 15 depicts the relative mass defect for each of the five assemblies with different numbers of partial defects. The results for UNCL are also included for comparison. The error bars represent the RSDs for 30 min counting time with a $2 \%$ systematic uncertainty included. As expected, larger mass defects were identified for assemblies with more rods replaced by rods filled with DU. The amounts of the mass defects determined by this collar are greater than those determined by UNCL for most of the corresponding cases, indicating this collar is more sensitive to partial defects than UNCL, which is desired as one of the primary safeguards goals is to detect partial defects. These mass defects were also compared with the standard deviations, in the form of " $2 \sigma$ " and " $3 \sigma$," under 10 and 30 min counting times for both detectors, and the results are shown in Table 14. In the table, " $2 \sigma$ " represents a confidence level of $68 \%$ and " $3 \sigma, " 95 \%$. If the mass defect is less than $2 \sigma$, by $68 \%$ of probability the mass defect was due to measurement uncertainties rather than other factors such as partial defects. If the mass defect is larger than a certain set threshold (e.g., $2 \sigma$ or $3 \sigma$ in this case), a partial defect case is detected and a red flag, indicated by a red "NO" in this table, is triggered in a safeguards inspection. As shown in this table, the plus collar can detect assemblies with smaller partial defects than UNCL, as indicated by the greater number of red "NO's" in the table. These results reemphasize that this collar is more sensitive to partial defects than UNCL. 


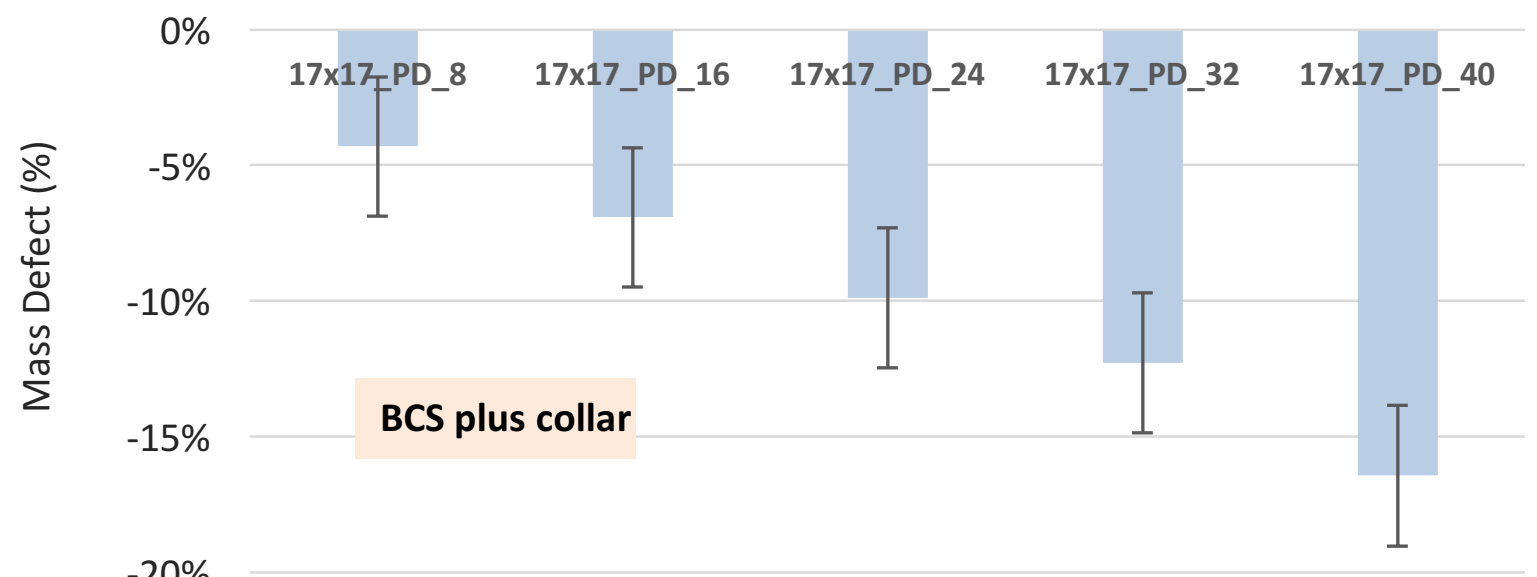

(a)

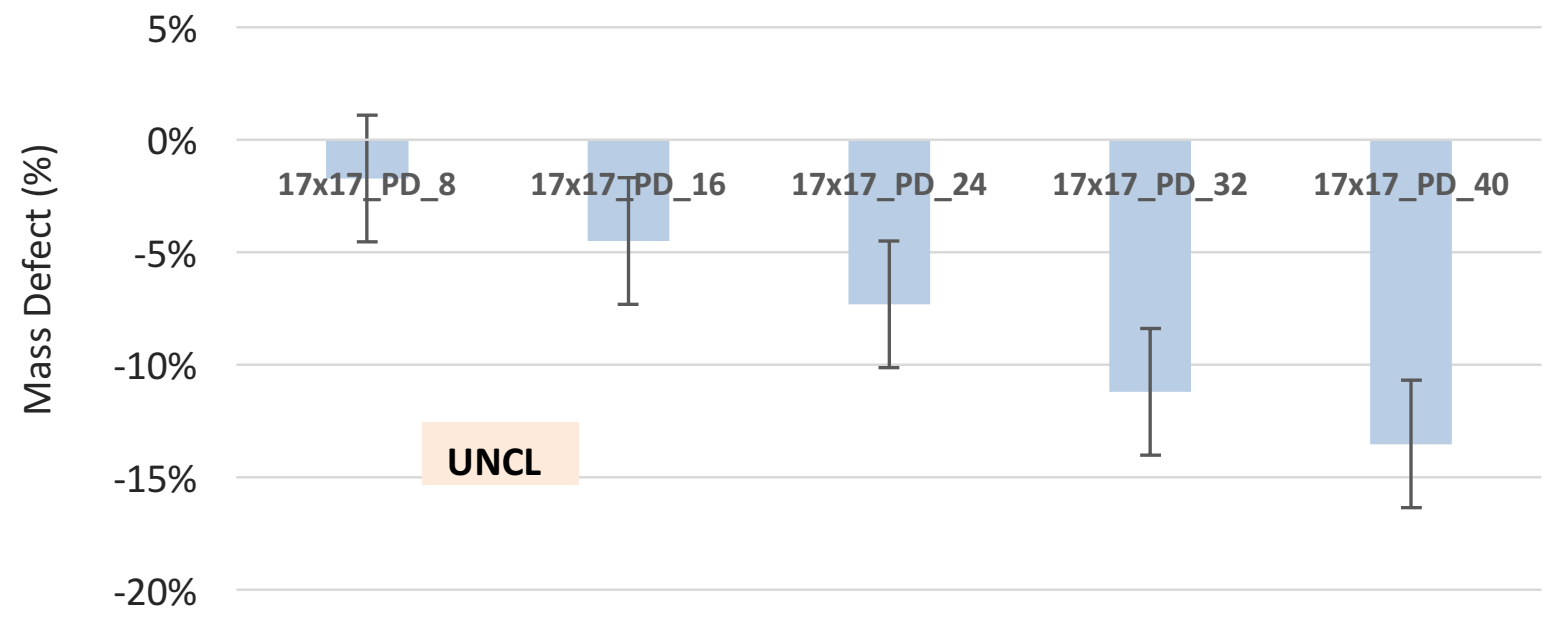

(b)

Figure 15. The relative mass defects of five assemblies with different numbers of partial defects for the BCS plus collar (a) and UNCL (b).

Table 14. Comparison of relative mass defects and RSDs for each partial defect case for the BCS plus collar and UNCL

\begin{tabular}{|c|c|c|c|c|c|c|c|c|c|c|}
\hline \multirow{2}{*}{$\begin{array}{l}\text { Number of } \\
\text { rods } \\
\text { substituted }\end{array}$} & \multicolumn{3}{|c|}{$\begin{array}{c}\text { BCS plus } \\
(t=10 \text { min })\end{array}$} & \multicolumn{3}{|c|}{$\begin{array}{c}\text { UNCL } \\
(t=10 \mathrm{~min})\end{array}$} & \multicolumn{2}{|c|}{$\begin{array}{c}\text { BCS plus } \\
(t=30 \text { min }\end{array}$} & \multicolumn{2}{|c|}{$\begin{array}{c}\text { UNCL } \\
(t=30 \text { min })\end{array}$} \\
\hline & $\begin{array}{c}\text { Mass } \\
\text { defect }\end{array}$ & $<2 \sigma ?$ & $<3 \sigma ?$ & $\begin{array}{l}\text { Mass } \\
\text { defect }\end{array}$ & $<2 \sigma ?$ & $<3 \sigma ?$ & $<2 \sigma ?$ & $<3 \sigma$ ? & $<2 \sigma ?$ & $<3 \sigma ?$ \\
\hline 0 & $0 \%$ & YES & YES & $0 \%$ & YES & YES & YES & YES & YES & YES \\
\hline 8 & $-4 \%$ & YES & YES & $-2 \%$ & YES & YES & YES & YES & YES & YES \\
\hline 16 & $-7 \%$ & NO & YES & $-4 \%$ & YES & YES & NO & YES & YES & YES \\
\hline 24 & $-10 \%$ & NO & YES & $-7 \%$ & YES & YES & NO & NO & NO & YES \\
\hline 32 & $-12 \%$ & NO & NO & $-11 \%$ & NO & YES & NO & NO & NO & NO \\
\hline 40 & $-16 \%$ & NO & NO & $-14 \%$ & NO & NO & NO & NO & NO & NO \\
\hline
\end{tabular}

Acronyms: $\mathrm{RSD}=$ relative standard deviation, $\mathrm{BCS}=$ boron-coated straw, and $\mathrm{UNCL}=$ Uranium Neutron Coincidence Collar. 


\subsection{SENSITIVITY TO GD RODS}

For this test, eighteen $17 \times 17$ fuel assemblies with different amounts of burnable poison (gadolinium) loadings were used to test the BCS plus collar's sensitivity to Gd rods. As shown in Figure 16, six different numbers of $\mathrm{Gd}$ rods were used in these assemblies $(4,8,12,16,20$, and 24), and three different gadolinium percentages were used in the Gd rods $(6,8$, and $10 \mathrm{wt} \%)$. By virtually inserting each assembly (with Gd rods) into the plus collar, the doubles rates were calculated using MCNP modeling. The doubles rates can also be inferred using the calibration function based on the amount of ${ }^{235} \mathrm{U}$ in the fuel assembly as if there were no Gd rods in the assembly. By comparing the simulated doubles rates against the inferred values, the relative reductions in doubles rates can be calculated, which can be attributed to the impacts of the Gd rods. Figure 17 shows the relative reductions in doubles rates as a function of gadolinium content in these tested assemblies. The results for three other detectors, UNCL, the Euratom Fast Collar (EFC), and the IAEA-developed FNCL, were also included for comparison. The results for UNCL, EFC, and FNCL were from Ref. [4], [2], and [3], respectively. As shown, the BCS plus collar is much less sensitive to gadolinium content (or Gd rods) than both UNCL and the Euratom Fast Collar, and the sensitivity of this collar was reduced by more than $40 \%$ compared with UNCL in high gadolinium content cases, which are the limiting cases in safeguards inspections. This collar was more sensitive to gadolinium than FNCL because FNCL is based on detection of fast neutrons that are naturally less sensitive to gadolinium. However, this collar is more practical than FNCL in terms of the data acquisition system, etc., as previously discussed.
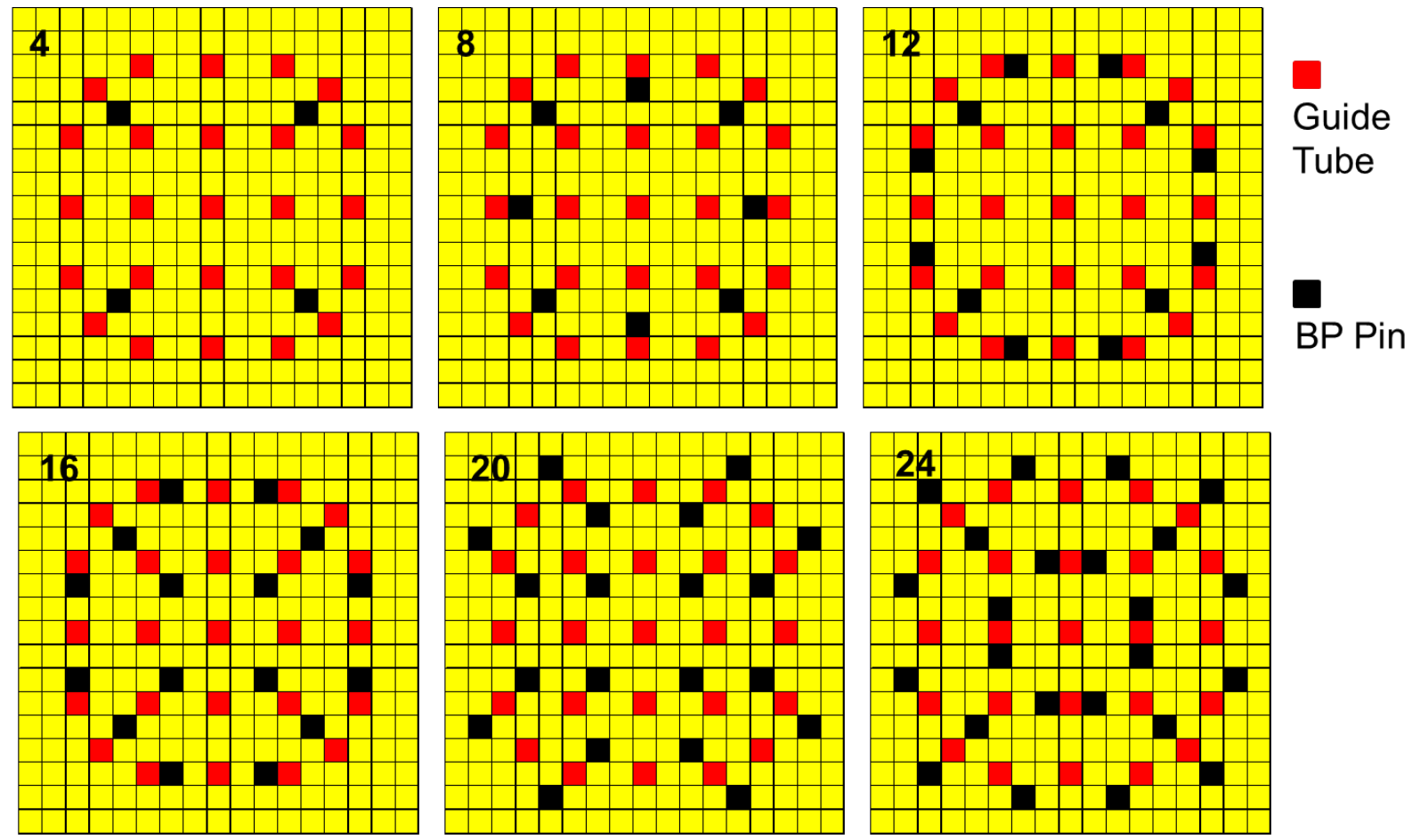

Figure 16. Number and distribution of Gd rods in each of the six test assemblies. ("BP" stands for burnable poison, which is a $\mathrm{Gd}$ rod in this case.) 


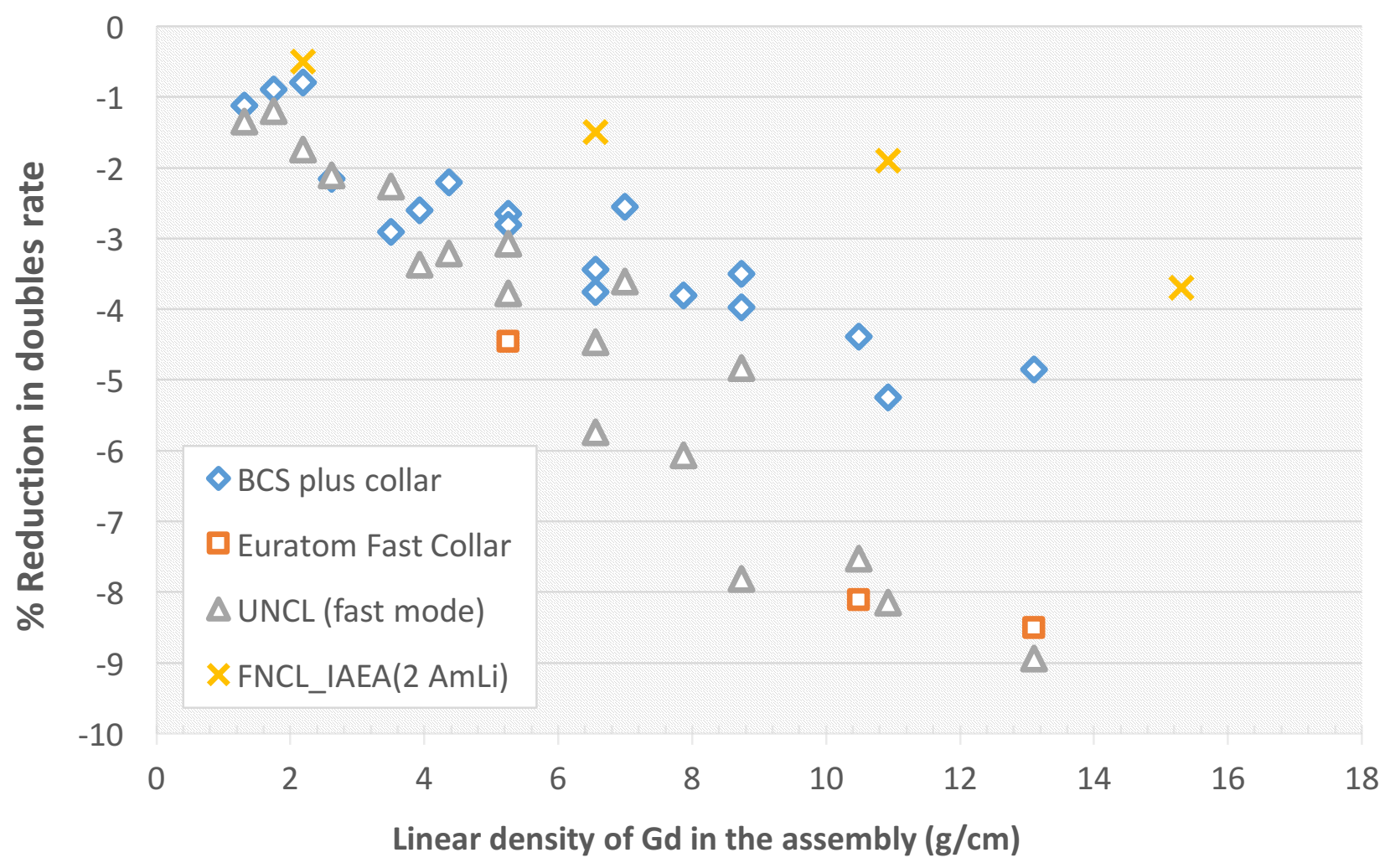

Figure 17. Relative reductions in doubles rates due to the Gd rods in each fuel assembly.

The simulated doubles rates were also used to infer the ${ }^{235} \mathrm{U} L D$ for the fuel assemblies using the calibration function. The inferred ${ }^{235} \mathrm{U}$ density was then compared to the true density in the assembly to calculate the mass defect.

Figure 18 shows the relative mass defects for each of the 18 test assemblies. "BP6_12" means the assembly has $12 \mathrm{Gd}$ rods and the gadolinium weight percentage in each $\mathrm{Gd}$ rod is $\overline{6} \%$. Again, the error bars represent the RSDs for 30 min counting time with a $2 \%$ systematic uncertainty included. The BCS plus collar detected much smaller mass defects than UNCL due to the presence of Gd rods in most corresponding assemblies, re-demonstrating that this collar is much less sensitive to Gd rods than UNCL.

Table 15 shows the comparison of relative mass defects and RSDs for each case with different gadolinium content for the BCS plus collar and UNCL. If the measured (simulated in this case) mass defect is larger than a certain set threshold (e.g., $2 \sigma$ or $3 \sigma$ in this case), a red flag, indicated by a red "NO" in this table, is triggered in a safeguards inspection. Unlike partial defect tests, red flags triggered by $\mathrm{Gd}$ rods are undesirable to inspectors because additional steps (e.g., corrections for the gadolinium) are required to resolve the red flags even if no ${ }^{235} \mathrm{U}$ is missing. As shown in this table, the BCS plus collar has many fewer red flags (the "NO's") than UNCL, indicating that this collar has much better performance in safeguarding fuel assemblies with Gd rods. 


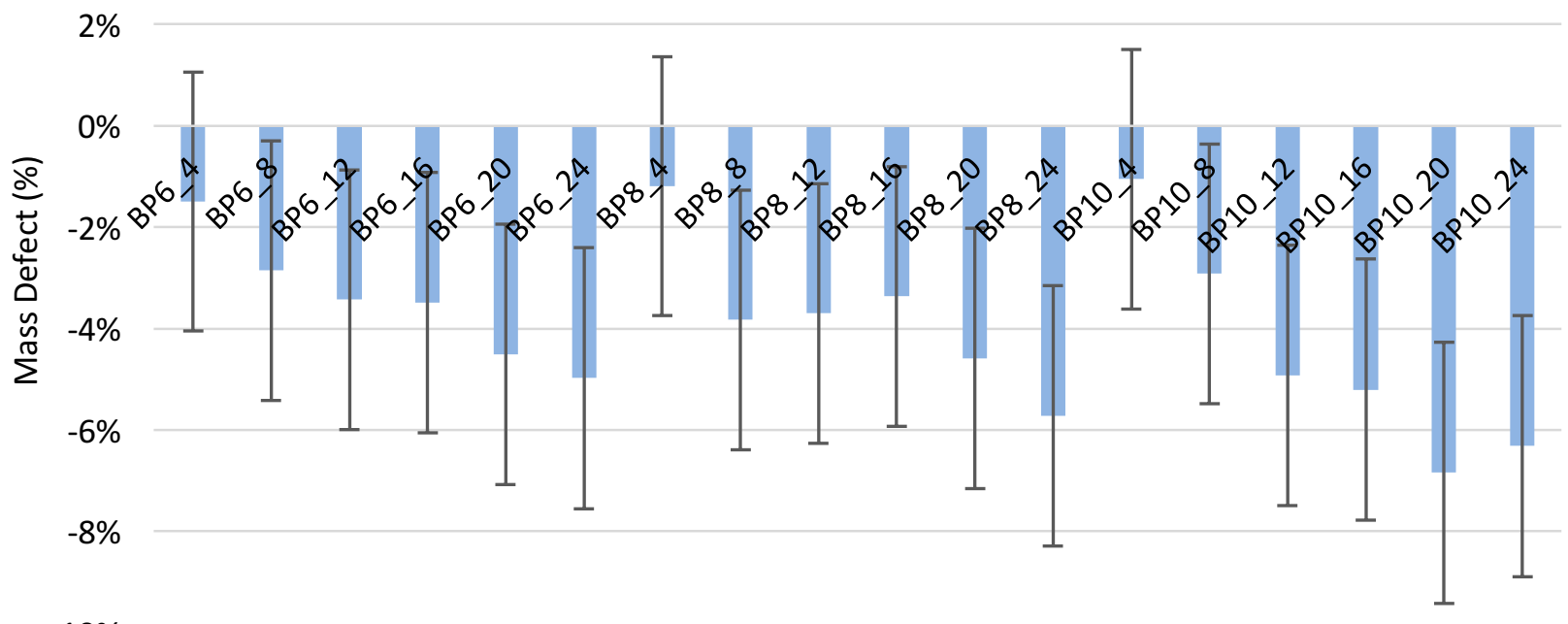
$-10 \%$

(a)

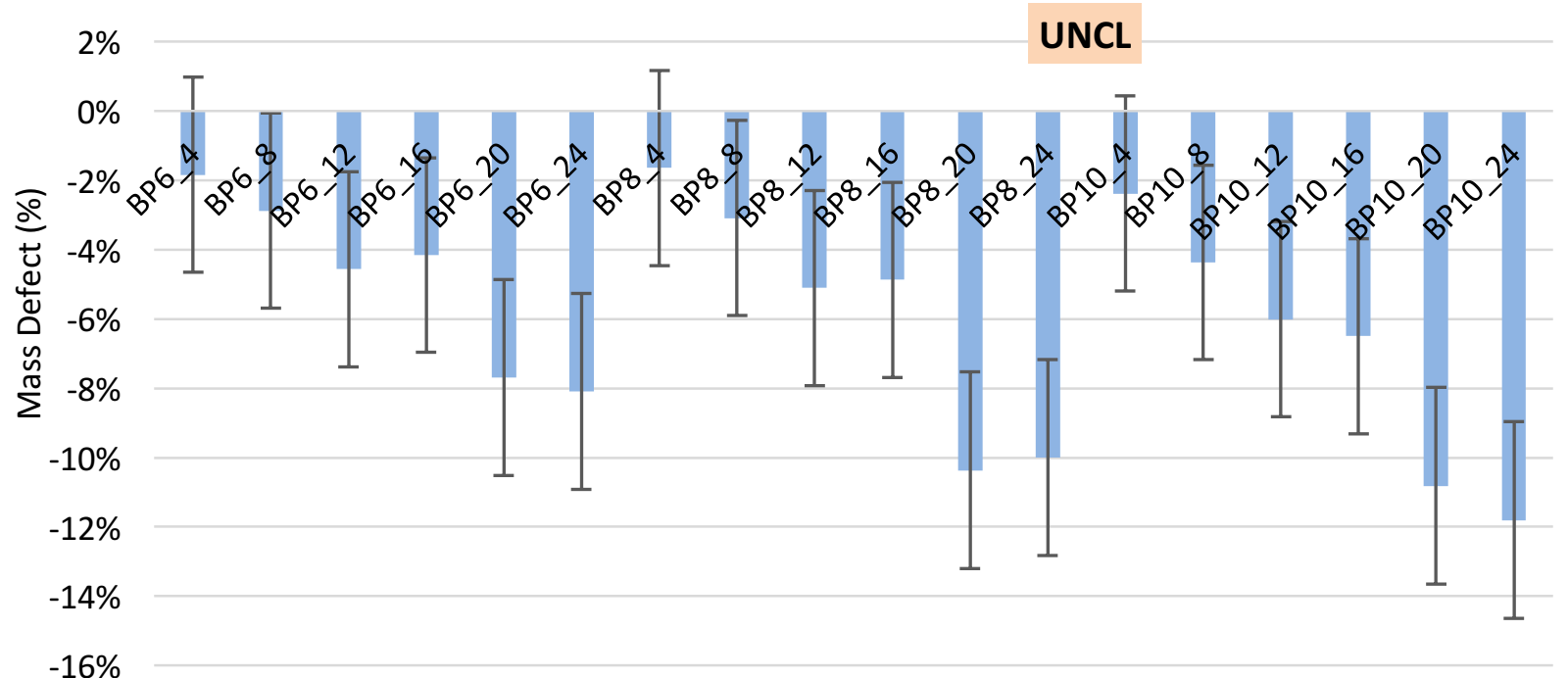

(b)

Figure 18. The relative mass defects of 18 assemblies with different amounts of gadolinium for the BCS plus collar (a) and UNCL (b). ("BP6_12" means that the assembly has $12 \mathrm{Gd}$ rods and the amount of gadolinium in each $\mathrm{Gd}$ rod is $6 \mathrm{wt} \%$.) 
Table 15. Comparison of relative mass defects and RSDs for each case with different gadolinium content for the BCS plus collar and UNCL

\begin{tabular}{|c|c|c|c|c|c|c|c|c|c|c|}
\hline \multirow{2}{*}{$\begin{array}{c}\text { Test } \\
\text { assembly }\end{array}$} & \multicolumn{3}{|c|}{$\begin{array}{l}\text { BCS plus collar } \\
\quad(t=10 \mathrm{~min})\end{array}$} & \multicolumn{3}{|c|}{$\begin{array}{c}\text { UNCL } \\
(t=10 \text { min })\end{array}$} & \multicolumn{2}{|c|}{$\begin{array}{c}\text { BCS plus collar } \\
(t=30 \mathrm{~m})\end{array}$} & \multicolumn{2}{|c|}{$\begin{array}{c}\text { UNCL } \\
(t=30 \text { min })\end{array}$} \\
\hline & $\begin{array}{c}\text { Mass } \\
\text { defect } \\
(\%)\end{array}$ & $<2 \sigma ?$ & $<3 \sigma ?$ & $\begin{array}{c}\text { Mass } \\
\text { defect } \\
(\%)\end{array}$ & $<2 \sigma$ ? & $<3 \sigma ?$ & $<2 \sigma ?$ & $<3 \sigma ?$ & $<2 \sigma ?$ & $<3 \sigma$ ? \\
\hline BP6_4 & -1.5 & YES & YES & -1.8 & YES & YES & YES & YES & YES & YES \\
\hline BP6_8 & -2.9 & YES & YES & -2.9 & YES & YES & YES & YES & YES & YES \\
\hline BP6_12 & -3.4 & YES & YES & -4.6 & YES & YES & YES & YES & YES & YES \\
\hline BP6_16 & -3.5 & YES & YES & -4.2 & YES & YES & YES & YES & YES & YES \\
\hline BP6_20 & -4.5 & YES & YES & -7.7 & YES & YES & YES & YES & NO & YES \\
\hline BP6_24 & -5.0 & YES & YES & -8.1 & NO & YES & YES & YES & NO & YES \\
\hline BP8_4 & -1.2 & YES & YES & -1.6 & YES & YES & YES & YES & YES & YES \\
\hline BP8_8 & -3.8 & YES & YES & -3.1 & YES & YES & YES & YES & YES & YES \\
\hline BP8_12 & -3.7 & YES & YES & -5.1 & YES & YES & YES & YES & YES & YES \\
\hline BP8_16 & -3.4 & YES & YES & -4.9 & YES & YES & YES & YES & YES & YES \\
\hline BP8_20 & -4.6 & YES & YES & -10.4 & NO & YES & YES & YES & NO & NO \\
\hline BP8_24 & -5.7 & YES & YES & -10.0 & NO & YES & NO & YES & $\mathrm{NO}$ & NO \\
\hline BP10_4 & -1.1 & YES & YES & -2.4 & YES & YES & YES & YES & YES & YES \\
\hline BP10_8 & -2.9 & YES & YES & -4.4 & YES & YES & YES & YES & YES & YES \\
\hline BP10_12 & -4.9 & YES & YES & -6.0 & YES & YES & YES & YES & NO & YES \\
\hline BP10_16 & -5.2 & YES & YES & -6.5 & YES & YES & NO & YES & NO & YES \\
\hline BP10_20 & -6.8 & NO & YES & -10.8 & NO & YES & NO & YES & NO & NO \\
\hline BP10_24 & -6.3 & YES & YES & -11.8 & NO & $\mathrm{NO}$ & $\mathrm{NO}$ & YES & $\mathrm{NO}$ & $\mathrm{NO}$ \\
\hline
\end{tabular}

Acronyms: RSD = relative standard deviation, $\mathrm{BCS}=$ boron-coated straw, and UNCL $=$ Uranium Neutron Coincidence Collar. 


\section{SUMMARY AND CONCLUSIONS}

As part of the NNSA's initiative to develop advanced NDA instruments based on technologies alternative to ${ }^{3} \mathrm{He}$ gas to replace UNCL for international safeguards, we designed and optimized two collars, the base and the plus model, in simulation space using BCS detectors. One of the primary goals of this overall effort is to reduce the new instrument's sensitivity to Gd rods compared with UNCL. We optimized the collars for improved detection efficiency, better counting statistics, and reduced Gd-rod sensitivities. These optimizations are documented in this report. Some of these proposed optimization strategies can be applied to other instruments including UNCL to reduce the sensitivity to Gd rods. Details about a previous BCS neutron counter prototype, HLNCC, were also described.

We also tested the collars using a suite of test problems and compared the results for the plus collar with those for UNCL. Based on these results and experience with the previous BCS prototype, the following conclusions can be made.

1. The calibration curves for the BCS plus collar were nearly identical to those for UNCL in fast mode, indicating that this collar will behave similarly to UNCL in discerning different ${ }^{235} \mathrm{U}$ enrichments in fuel assemblies, and can be used immediately with existing algorithms in INCC.

2. The BCS plus collar is more sensitive to partial defects than UNCL, which is desired by safeguards inspectorates because one of the primary safeguards goals is to detect partial defects.

3. The BCS plus collar is much less sensitive to Gd rods in the fuel assemblies than UNCL, which is one of the key motivations for this project. This is becoming increasingly important as more gadolinium is used in modern fuel assembly designs.

4. The BCS plus collar will be a practical ${ }^{3} \mathrm{He}$-free replacement for UNCL because it has only a slightly larger footprint and can share the same data acquisition system as UNCL. The straws used in this collar have been proven to be stable and reliable in other detectors (e.g., portal monitors) using the same technology in the field. The engineering development is low risk using commercially available components.

5. The BCS detectors use inexpensive materials. The successful demonstration of the BCS HLNCC prototype demonstrated that $\mathrm{BCS}$ is a mature, practical, and economical alternative technology for neutron coincidence counting. Since the BCS HLNCC was made, higher performance straw designs have become available, which can benefit the collars in this project.

6. Physics limits the ability to be insensitive to Gd rods for all the technologies studied under this NNSA program. Practicality and costs will become prominent deciding factors on which technologies to choose for further development.

7. Our design has introduced several noval features for the first time and these should be demonstrated experimentally. 


\section{REFERENCES}

[1] H. Menlove, J. Stewart, S. Qiao and T. Wenz, "Neutron collar calibration and evaluation for assay of LWR fuel assemblies containing burnable neutron absorbers," Los Alamos National Laboratory, LA11965-MS, 1990.

[2] L. Evans, M. Swinhoe, H. Menlove, P. Schwalbach, P. Baere and M. Browne, "A new fast neutron collar for safeguards inspection measurements of fresh low enriched uranium fuel assemblies containing burnable poison rods," Nuclear Instruments and Methods in Physics Research A, vol., no. 729, pp. 740-746, 2013.

[3] T. Lee, A. Tomanin, M. Mayorov, J. Beaumont and L. Holzleitner, "Liquid Scintillator-Based Fast Neutron Coincidence Counter for Fresh Nuclear Fuel Measurements," in Advances in Nuclear Nonproliferation Technology \& Policy Conference, Santa Fe, 2016.

[4] A. Belian, A. Iyengar, A. Dougan and e. al., "Advanced Neutron Detection Technology Rodeo," in 2017 ESARDA Symposium (to appear), Dusseldorf, Germany, 2017.

[5] B. Rossi and H. Staub, Ionization chambers and counters: Experimental techniques (First Edition), McGraw-Hill Book Company, Inc., 1949.

[6] P. Dighe and D. Das, "Performance studies of boron lined proportional counters for reactor applications," Nuclear Instrument and Methods A, no. 770, pp. 29-35, 2015.

[7] B. Ende, J. Atanackovic, A. Erlandson and G. Bentoumi, "Use of GEANT4 vs. MCNP for the characterization of boron-lined neutron detector," Nuclear Instrument and Methods A, no. 820, pp. 40-47, 2016.

[8] J. Lacy, A. Athanasiades, C. Martin, L. Sun and G. Vazquez-Flores, "The evolution of neutron strw detector applications in homeland security," IEEE Trans on Nucl Sci, vol. 60, no. 2, pp. 1140-1146, 2013.

[9] R. Runkle, A. Bernstein and P. Vanier, "Securing special nuclear material: Recent advances in neutron detection and their role in non- proliferation," J. Appl. Phys., vol. 108, p. 111101, 2010.

[10] J. Dolan, A. Dougan, D. Peranteau and S. Croft, "An International View on 3He Alternatives for Nuclear Safeguards," Journal of Nuclear Materials Management, vol. 43, no. 3, pp. 17-29, 2015.

[11] J. Lacy, A. Athanasiades, L. Sun, C. Martin and G. Vazquez-Flores, "A straw based HLNCC multiplicity counter with improved FOM in the same form factor," in INMM 55th Annual Meeting, Atlanta, GA, 2014.

[12] A. Simone, S. Croft and J. Hayward, "Performance of a HLNCC Boron Coated Straw Detector for International Safeguards Applications," in IEEE-2016, Dallas, TX, 2016.

[13] J. Lacy and A. Athanasiades, Private communications with Proportional Technologies, Inc., 2016. 
[14] S. Croft, M. Swinhoe and V. Henzl, "Á Priori Precision Estimation for Neutron Triples Counting," in The Second International Conference on Advancements in Nuclear Instrumentation, Measurement Methods and their Applications - ANIMMA, Ghent, Belgium, 2011.

[15] S. Croft, P. Blanc and N. Menaa, "Precision of the accidentals rate in neutron coincidence counting," in Waste Management Symposium, Phoenix, Arizona, 2010.

[16] B. Goddard, S. Croft, A. Lousteau and P. Peerani, "Evaluation of Am-Li neutron spectra data for active well type neutron multiplicity measurements of uranium," Nucl. Instrum. and Meths. in Phys. Res. A, vol. 830, pp. 256-264, 2016.

[17] D. Pelowitz(editor), MCNP6 User's Manual, Los Alamos, NM: Los Alamos National Laboratory, LA-CP-13-00634, 2013. 


\section{APPENDIX: ELECTRONIC EFFICIENCY FACTOR (EEF)}

\section{Introduction}

The ${ }^{10} \mathrm{~B}(\mathrm{n}, \alpha)$ Li interactions taking place in the ${ }^{\mathrm{enr}} \mathrm{B}_{4} \mathrm{C}$ coating are only registered if one of the reaction products emerges from the coating with sufficient energy to ionize the counter gas above some detectable minimum charge threshold. This probability of detection per neutron absorption is called the Electronic Efficiency Factor (EEF). One way to estimate the singles, doubles, and triples counting rates using MCNP simulations is to use the standard coincidence capture tally capability as if all the interactions are detected, and then to scale the $\mathrm{S}, \mathrm{D}$, and T rates per source event predicted by EEF, $\mathrm{EEF}^{2}$ and $\mathrm{EEF}^{3}$ respectively.

The EEF may itself be estimated by using MCNP to compute an energy deposition histogram for the $\alpha$ and heavy-charge particle pair emitted by the ${ }^{10} \mathrm{~B}(\mathrm{n}, \alpha)^{7} \mathrm{Li}$ process. At the time of writing the Beta version 6.1.1 is available with improved charged transport treatment.

Here we take an alternative approach to estimating the EEF which serves as a simple and independent check on the MCNP energy deposition or other approaches.

\section{Method}

Recall the ${ }^{10} \mathrm{~B}(\mathrm{n}, \alpha)$ reaction follows two branches. The energetics of the reaction branches are summarized in Table A.1. The dominant reaction channel leaves the ${ }^{7} \mathrm{Li}$ product nucleus in its short lived first excited state that subsequently decays with the emission of a $(477.596 \pm 0.002) \mathrm{keV}$ gamma-ray [A.1] which is subject to Doppler broadening.

We estimate the branching probability, $\beta^{*}$, to the first excited state to be $(0.93700 \pm 0.00013)$. This value is the weighted mean of two high accuracy determinations made by Deruytter and Perlfer [A.2], and Stelts et al [A.3], respectively. The uncertainty is quoted as the associated external standard error and is negligible in the context of our present discussion.

Table A.1. ${ }^{10} \mathrm{~B}(\mathrm{n}, \alpha)^{7} \mathrm{Li}$ energetics based on mass data from TOI'96 [A.1] assuming non-relativistic kinematics.

\begin{tabular}{|l|l|l|l|}
\hline Reaction Channel & Q-value, $\mathrm{keV}$ & $\begin{array}{l}\alpha \text {-particle kinetic } \\
\text { energy, } \mathrm{keV}\end{array}$ & $\begin{array}{l}\text { Li-ion kinetic energy, } \\
\mathrm{keV}\end{array}$ \\
\hline${ }^{7} \mathrm{Li}^{\mathrm{gs}}$ & $2789.5 \pm 0.6$ & 1776.2 & 1013.3 \\
\hline${ }^{7} \mathrm{Li}^{*}$ & $2311.9 \pm 0.6$ & 1472.1 & 839.8 \\
\hline
\end{tabular}

Based on information provided by the vendor [A.4] the ${ }^{\text {enr }} \mathrm{B}_{4} \mathrm{C}$ coating was modeled as a uniform layer of $\mathrm{B}_{4} \mathrm{C}$ (although the structure of boron carbide is generally considered to be complex and somewhat carbon deficient). The boron was taken to be enriched to 96 at $\%$ in ${ }^{10} \mathrm{~B}$ and the density of the coating was taken to be $2.38 \mathrm{~g} / \mathrm{cm}^{3}$. Note at 96 at $\%$ enrichment the ${ }^{10} \mathrm{~B}$ weight fraction in the carbide is approximately 0.736; it is about 0.769 for 100 at $\%$ material. 
The fraction, $f\left(E_{t h}\right)=f\left(E_{t h} ; P, t\right)$, of charged particle reaction products of a given kind $P$, that emerge from a uniform deposit of thickness $t$, into the counter gas with an energy above the threshold energy value $E_{t h}$ (assuming that particles which emerge at grazing angles and perpendicular to the surface are equally effective at creating detectable charge) was estimated analytically using the following formulae [A.5, A.6, and A.7]

For $t<\left[R_{p}\left(E_{o}\right)-R_{p}\left(E_{t h}\right)\right]$ :

$$
f\left(E_{t h}\right)=\frac{1}{2} \cdot\left[1-\frac{t}{2 \cdot\left[R_{p}\left(E_{o}\right)-R_{p}\left(E_{t h}\right)\right]}\right]
$$

where

$t$ is the thickness of the deposit

$R_{p}\left(E_{o}\right)$ is the projected range of the particular particle $P$ at the initial kinetic energy $E_{o}$

$R_{p}\left(E_{t h}\right)$ is the projected range of the particular particle $P$ with kinetic energy $E_{t h}$.

Note when the coating is thin $f\left(E_{t h}\right)$ takes on a maximum value of one-half. This corresponds to the case of all the particles which are emitted in the direction of the gas being registered.

For $t>\left[R_{p}\left(E_{o}\right)-R_{p}\left(E_{t h}\right)\right]$ :

$$
f\left(E_{t h}\right)=\frac{\left[R_{p}\left(E_{o}\right)-R_{p}\left(E_{t h}\right)\right]}{t} \cdot \frac{1}{4}
$$

which reflects the fact that only the fraction $\frac{\left[R_{p}\left(E_{o}\right)-R_{p}\left(E_{t h}\right)\right]}{t}$ of the deposit is within striking distance of the surface and for which the limiting case of the thin deposit formula applies $\left(f\left(E_{t h}\right)=\frac{1}{4}\right)$.

A separate calculation is needed to each particle type, $\alpha$ and ${ }^{7} \mathrm{Li}$, and the two probabilities are then summed to get the detection probability per neutron capture. A separate calculation is also performed for each branch and the two reaction branches are appropriately weighted and summed. To summarize:

$$
E E F=\left(1-\beta^{*}\right) \cdot\left[f\left(E_{t h} ; \alpha_{0}, t\right)+f\left(E_{t h} ; L i^{g s}, t\right)\right]+\beta^{*} \cdot\left[f\left(E_{t h} ; \alpha_{1}, t\right)+f\left(E_{t h} ; L i^{*}, t\right)\right]
$$

where the explicit particle dependence is being used to denote the functional dependence on the projected range of the particular reaction product particle.

Ranges for $\alpha$-particles and ${ }^{7}$ Li-ions (7.016 atomic mass units) were calculated using the SRIM code [A.8]. A utility was created to calculate the Electronic Efficiency Factor (EEF) for a range of threshold values (40 to $200 \mathrm{keV}$ ) given a user entered layer thickness (in $\mu \mathrm{m}$ ). A typical threshold setting is approximately $70 \mathrm{keV}$, although, a higher value may be used in high mixed $\gamma / \mathrm{n}$ environments. The user is also invited to enter the ${ }^{10} \mathrm{~B}$ enrichment and boron carbide density. These are needed to convert the SRIM ranges computed for ${ }^{\text {nat }} \mathrm{B}_{4} \mathrm{C}$ at $2.38 \mathrm{~g} / \mathrm{cm}^{3}$ to the actual material properties of interest (in other words the apparent areal density of the coating for a given thickness depends on the enrichment, but the particle ranges depend on the atomic number density). The scaled ranges, $R$, are obtained from the standard reference (SRIM) case values, $R_{o}$, on the basis that the range is inversely proportional to the area density of boron carbide molecules, thus: 


$$
R=\frac{\rho_{o} / A_{o}}{\rho / A} \cdot R_{o}
$$

where $\rho / A$ is the density to molecular molar mass ratio of the deposit and $\rho_{o} / A_{o}$ is the corresponding value for the reference SRIM calculations. As an example at 96 at $\%$ enrichment and a density of 2.38 $\mathrm{g} / \mathrm{cm}^{3}$ the numerical value of the ratio of ratios if about 0.9451 .

An example calculation of the EEF as a function of threshold energy is shown in Figure A.1 for the case of a $2 \mu \mathrm{m}$ layer of boron carbide density of $2.38 \mathrm{~g} / \mathrm{cm}^{3}$ containing 96 at $\%$ enriched boron. At a threshold of $70 \mathrm{keV}$ the EEF is seen to be approximately 0.51 .

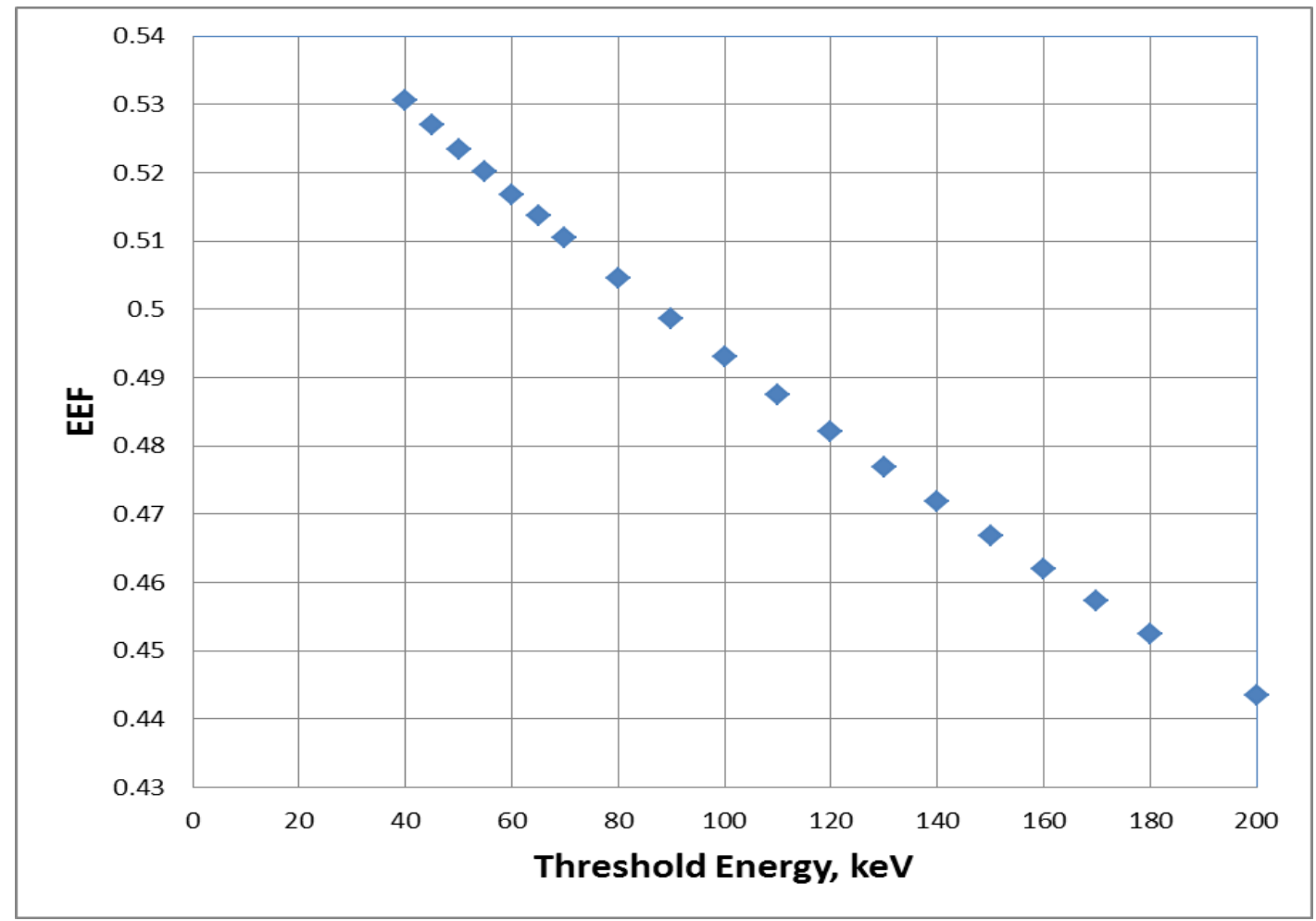

Figure A.1. Plot of the calculated EEF vs energy threshold for 96 at $\%$ enriched boron and $2 \mu \mathrm{m}$ coating of boron carbide at a density of $2.38 \mathrm{~g} / \mathrm{cm}^{3}$.

\section{Comparison to the PTI Formula}

Lacy et al [A.9] developed at different analytical treatment. They use:

$$
E E F=\varepsilon_{r e g} \cdot \varepsilon_{e s c}
$$

where

$\varepsilon_{e s c}$ is the probability that a reaction product will enter the gas (at all)

and

$\varepsilon_{r e g}$ is the average probability that the entering reaction product will be detected. 
For all practical applications of interest we need only concern ourselves with thin deposits (upto about 2 $\mu \mathrm{m})$. For ${ }^{\text {enr }} \mathrm{B}_{4} \mathrm{C}$ (I assume 96 at $\%$ enrichment in ${ }^{10} \mathrm{~B}$ ) of $2.38 \mathrm{~g} / \mathrm{cm}^{3}$ Lacy et al use the following:

$$
\begin{aligned}
\varepsilon_{e s c} & \approx 1-0.223 \cdot T, \quad \text { for } T \leq 1.69 \mu m \\
& \approx 0.5+\frac{0.423}{T}-\frac{T}{13.4}, \quad \text { for } 1.69 \mu m<T \leq 3.35 \mu m
\end{aligned}
$$

where is the thickness of the deposit in $\mu \mathrm{m}$, and,

$$
\varepsilon_{\text {reg }} \approx 0.9
$$

Over the interval $0.5 \mu \mathrm{m}$ to $2 \mu \mathrm{m}$ the expression for $\varepsilon_{\text {esc }}$ was shown to produce results in good agreement to MCNPX energy deposition calculations (comparable to the relative statistical sampling uncertainty of $1 \%$ ). For coating thicknesses of $1 \mu \mathrm{m}$ and $2 \mu \mathrm{m}$ we obtain the following estimates for the EEF of:

$$
\begin{aligned}
& E E F(T=1 \mu \mathrm{m})=\varepsilon_{r e g} \cdot \varepsilon_{e s c} \approx 0.90 \cdot 0.777 \approx 0.70 \\
& E E F(T=2 \mu \mathrm{m})=\varepsilon_{r e g} \cdot \varepsilon_{e s c} \approx 0.90 \cdot 0.562 \approx 0.51
\end{aligned}
$$

The latter result agrees rather well with the result presented above based on the algorithm to estimate the EEF developed in this work. This is perhaps not surprising because the value for the factor $\varepsilon_{r e g}$ was chosen empirically to match the experimentally obtained efficiency for BCS assemblies based on straws with thicknesses in this general range (say, $0.85 \mu \mathrm{m}$ to $1.49 \mu \mathrm{m}$ ) operated with a threshold of about 73 $\mathrm{keV}$. The EEF calculation based on the algorithm of Lacy et al [2013] is also available in the spreadsheet utility. However, it is uncertain what value of $\varepsilon_{r e g}$ is appropriate to use if a different threshold setting is used or if the thickness is outside the range for which it was developed.

\section{Comparison to Direct Calculation}

Two High Level Coincidence Counter (HLNCC) variants incorporating boron coated proportional gas detectors were modeled using MCNPX. The first was based on 160 boron coated proportional tubes ( $25.4 \mathrm{~mm}$ diameter arranged in 5 concentric rings about the $17.5 \mathrm{~cm} \mathrm{ID,} \mathrm{Cd} \mathrm{lined} \mathrm{assay} \mathrm{cavity.} \mathrm{The}$ second variant based on 649 boron coated straw detectors of $4.8 \mathrm{~mm}$ diameter arranged in 8 concentric rings. F6 and F8 tallies were used to tally the charged particle energy deposition in the quench gas. The plots shown in Figures A.2 and A.3 show the fraction of neutrons captured in the boron coatings and depositing energy in the quench gas greater than the threshold energy. The detector layout for the two geometries is shown in Figure A.4.

In both cases the boron coating thickness was $2 \mu \mathrm{m}$ consisting of ${ }^{\mathrm{enr}} \mathrm{B}_{4} \mathrm{C}$ where the boron is 96 at $\%$ enriched in ${ }^{10} \mathrm{~B}$. The quench gas in both cases was a standard $\mathrm{P} 10\left(90 \% \mathrm{Ar}\right.$ and $10 \% \mathrm{CH}_{4}$ by partial pressure) mixture. The fill pressure was XXX atm. We see that the results are similar in the two cases suggesting that the radius of curvature is not a strong influence so that the plane coating approximation is satisfactory. With a threshold setting of about $70 \mathrm{keV}$ we see that once again the estimate for the EEF is about 0.51 . 


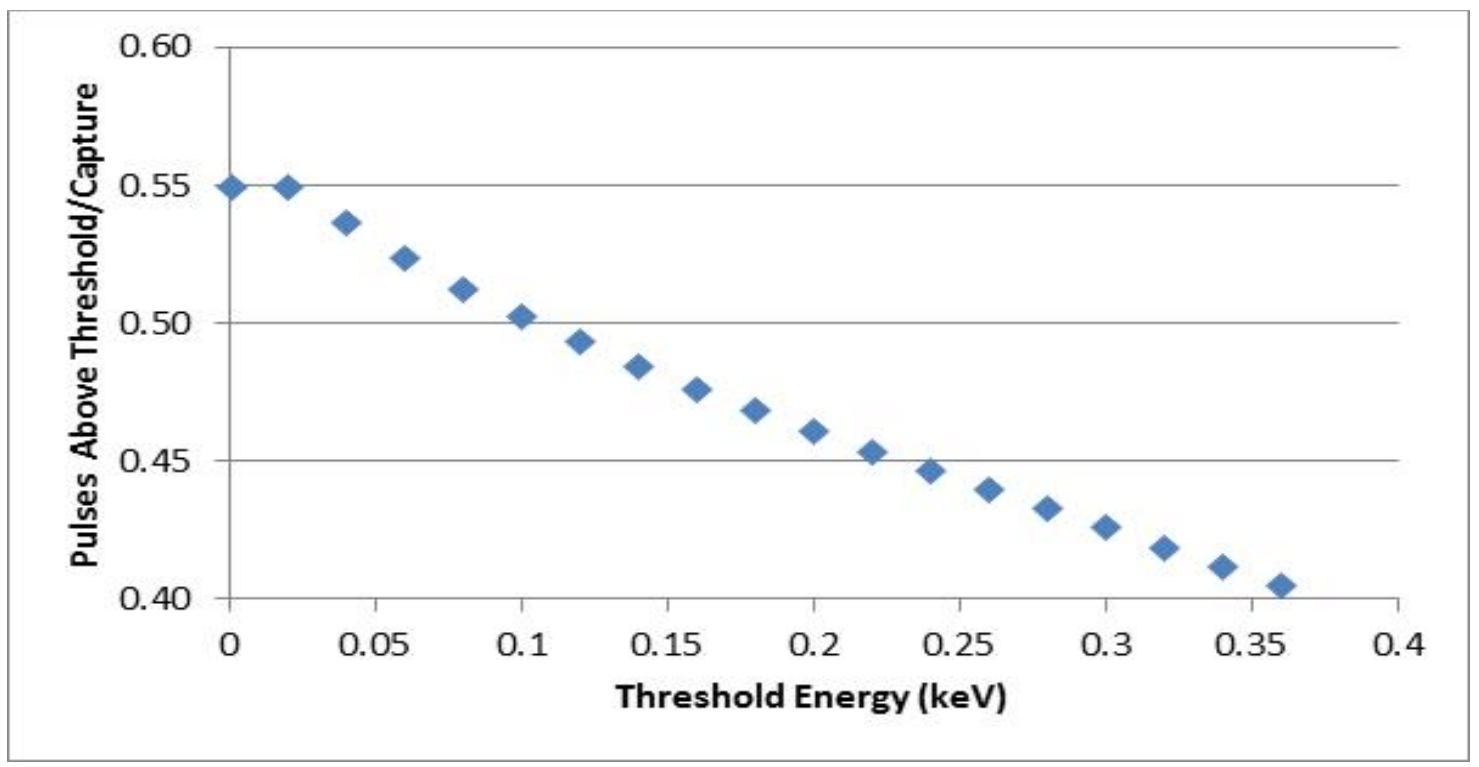

Figure A.2. Fraction of pulses depositing energy above the threshold setting for neutrons detected in 25.4 $\mathrm{mm}$ diameter boron coated proportional tubes.

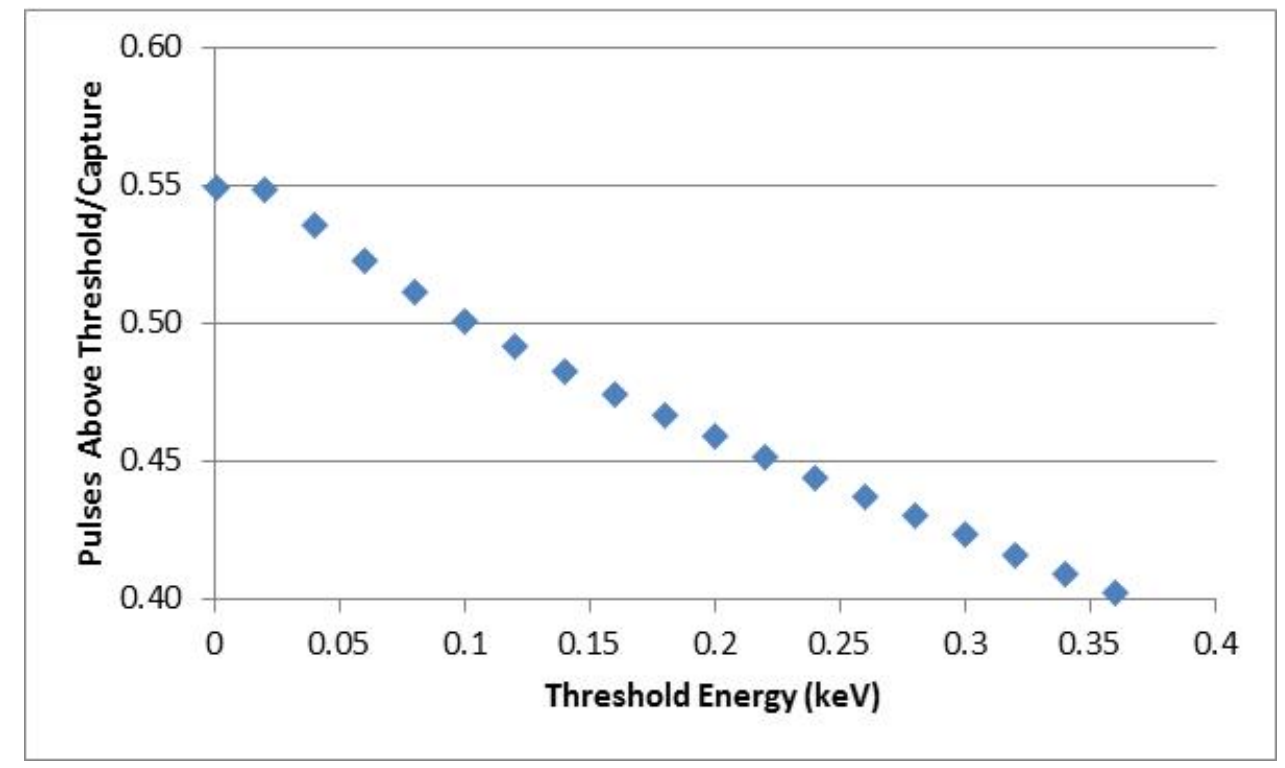

Figure A.3. Fraction of pulses depositing energy above the threshold setting for neutrons detected in the $4.8 \mathrm{~mm}$ diameter boron coated straw detectors. 

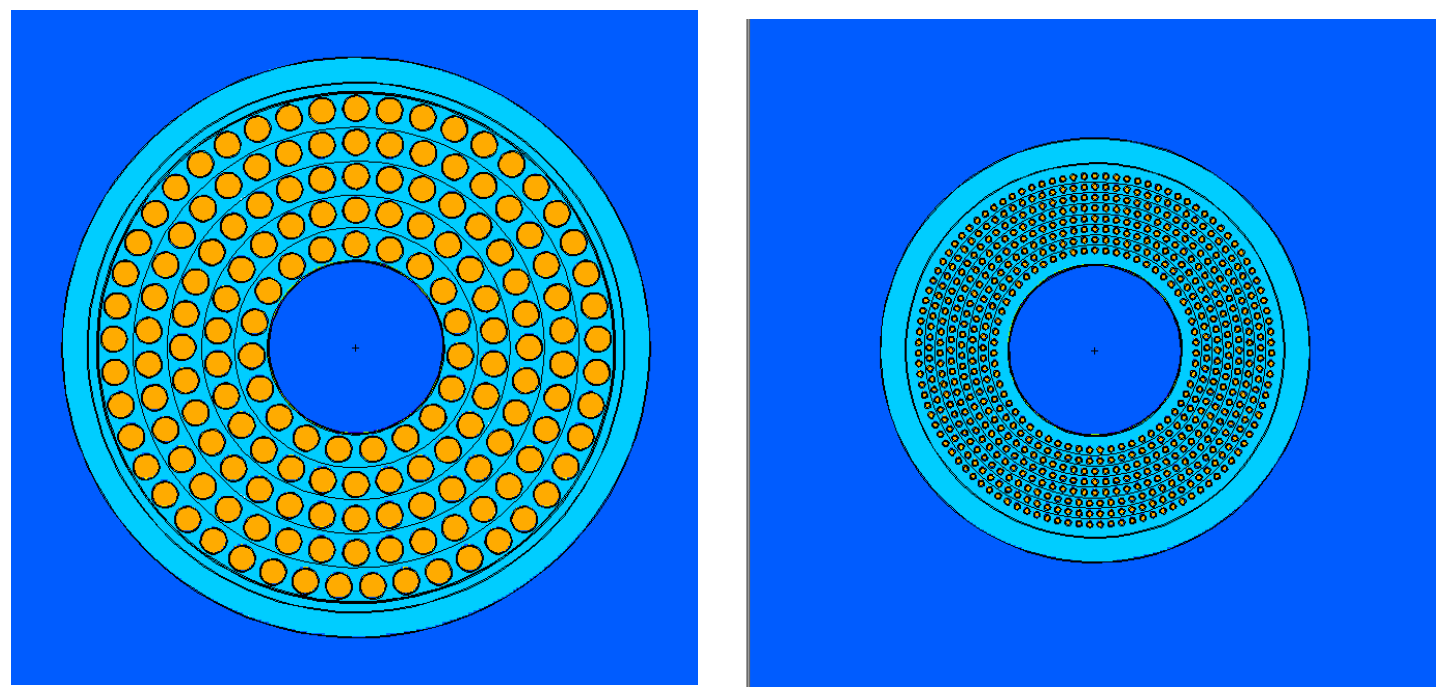

Figure A.4. Detector layout used in the MCNPX simulations for the HLNCC alternative systems using the traditional $25.4 \mathrm{~mm}$ diameter proportional tubes (left) and the $4.8 \mathrm{~mm}$ diameter straws (right).

\section{References}

[A.1] R.B. Firestone and V.S. Shirley (Eds), Table of Isotopes, Eighth Edition, John Wiley \& Sons, Inc. (1996). ISBN 0-471-14918-7 (two volume set).

[A.2] A.J. Deruytter and P. Pelfer, "Precise determination of the branching ratio and Q-value of the ${ }^{10} \mathrm{~B}(\mathrm{n}, \alpha)^{7} \mathrm{Li}$ reaction and the Q-value of the ${ }^{6} \mathrm{Li}(\mathrm{n}, \alpha)^{3} \mathrm{H}$ reaction," J of Nucl Energy 21(1967)833-845.

[A.3] M.L. Stelts, R.E. Chrien, M Goldhaber, and MJ Kenny, "Angular distributions of the ${ }^{6} \mathrm{Li}(\mathrm{n}, \mathrm{t})^{4} \mathrm{He}$ and ${ }^{10} \mathrm{~B}(\mathrm{n}, \alpha){ }^{7} \mathrm{Li}$ reactions at 2 and $24 \mathrm{keV}$," Phys Rev C19(4)(1979)1159-1167.

[A.4] Proportional Technologies Inc., Houston Texas, USA

[A.5] B.B. Rossi and H.H. Staub, Ionization chambers and counters: Experimental techniques, McGrawHill Book Company, Inc. (1949).

[A.6] S. Croft, "The extrapolation of fission fragment pulse-height distributions recorded using pulse ionisation fission chambers to zero amplitude," Applied Radiation and Isotopes: International Journal of Radiation Applications and Instrumentation Part A 41 (1990) 207-210.

[A.7] Z.W. Bell, M.A. Buckner, and D.B. Smith, "A ${ }^{10}$ B-based solid state thermal neutron detector," Proc. $37^{\text {th }}$ Annual INMM Meeting, Naples, Florida, USA, July 28 - August 1, 1996(1996)414-419.

[A.8] SRIM-2013.00, “The Stopping and Range of Ions in Matter," Available at: www.SRIM.org

[A.9] J.L. Lacy, A. Athanasiades, C.S. Martin, L. Sun, and G.L. Vazquez-Flores, "The evolution of neutron straw detector applications in homeland security," IEEE Transactions on Nuclear Science 60(2)(April 2013)1140-1146. 